Article

\title{
Organophosphorus Polyurethane Ionomers as Water Vapor Permeable and Pervaporation Membranes
}

\author{
Ilsiya M. Davletbaeva ${ }^{1, *}$, Oleg O. Sazonov ${ }^{1, *} \mathbb{D}$, Ilyas N. Zakirov ${ }^{1} \mathbb{D}$, Askhat M. Gumerov ${ }^{1}$, \\ Alexander V. Klinov ${ }^{2}\left({ }^{\circ}\right.$, Azat R. Fazlyev ${ }^{2} \mathbb{C}$ and Alexander V. Malygin ${ }^{2}$ \\ 1 Department of Synthetic Rubber, Kazan National Research Technological University, 68 Karl Marx st., \\ Kazan 420015, Russia; zakirovilyas1996@gmail.com (I.N.Z.); gumerov_a@mail.ru (A.M.G.) \\ 2 Department of Chemical Process Engineering, Kazan National Research Technological University, \\ 68 Karl Marx st., Kazan 420015, Russia; alklin@kstu.ru (A.V.K.); fazlyev.azat@gmail.com (A.R.F.); \\ mav@kstu.ru (A.V.M.) \\ * Correspondence: davletbaeva09@mail.ru (I.M.D.); sazonov.oleg2010@gmail.com (O.O.S.)
}

\section{check for} updates

Citation: Davletbaeva, I.M.; Sazonov, O.O.; Zakirov, I.N.; Gumerov, A.M.; Klinov, A.V.; Fazlyev, A.R.; Malygin, A.V. Organophosphorus

Polyurethane Ionomers as Water Vapor Permeable and Pervaporation Membranes. Polymers 2021, 13, 1442. https://doi.org/10.3390/ polym13091442

Academic Editor: Johannes Carolus (John) Jansen

Received: 28 March 2021

Accepted: 27 April 2021

Published: 29 April 2021

Publisher's Note: MDPI stays neutral with regard to jurisdictional claims in published maps and institutional affiliations.

Copyright: (c) 2021 by the authors. Licensee MDPI, Basel, Switzerland. This article is an open access article distributed under the terms and conditions of the Creative Commons Attribution (CC BY) license (https:// creativecommons.org/licenses/by/ $4.0 /)$.

\begin{abstract}
Organophosphorus polyurethane ionomers (AEPA-PU) based on aminoethers of orthophosphoric acid (AEPA) were obtained and studied as pervaporation membrane materials for separating isopropanol/water mixtures. The regularities of the change in the water vapor permeability of AEPA-PU were also investigated. It has been established that an increase of solute content in the composition of the urethane-forming system and the content of ionogenic groups in AEPA leads to a noticeable increase in the vapor permeability of the resulting film materials. An increase in water vapor permeability values is accompanied by a significant increase in the pervaporation characteristics of AEPU-PU. It was shown that the conditions promoting clustering of phosphate anions cause an increase in the values of the vapor permeability coefficient of AEPA-PU obtained using polyoxypropylene glycol. However, the hydrophobicity of the polypropylene glycol surrounding the clusters makes it difficult for water to move through the polymer matrix. Due to the hydrophilicity of polyoxyethylene glycol, the highest values of water vapor permeability and pervaporation characteristics are achieved for AEPA-PU synthesized using PEG.
\end{abstract}

Keywords: pervaporation membranes; polyurethane ionomers; dehydration; water vapor permeability; isopropanol

\section{Introduction}

Pervaporation separation using polymer membranes is promising in the processes of isopropanol (IPA) dehydration [1-4]. It is known that distillation methods traditionally used for these purposes have high-energy consumption and have limitations in the separation of azeotropic mixtures [5]. The use of traditional separation methods, in this case, is economically impractical and leads to environmental pollution. Isopropanol is widely used in modern semiconductor and microelectronic industries as a solvent and cleaning agent, the extraction and purification of natural products, as a binding agent, polymerization modifier, deicing agent and preservative, and as an aerosol solvent in medicine. The demand for IPA is growing every year, which contributes to an increase in the price of the pure substance. In addition, IPA waste is extremely harmful to the environment and requires high disposal costs. Therefore, the recovery and reuse of IPA are important from both economic and environmental points of view. The main problem in separating IPA from wastewater is the formation of an azeotropic mixture, which consists of 87.4 wt. $\%$ IPA and 12.6 wt.\% water.

Pervaporation membranes have been developed from several hundred types of polymeric materials [6-20]. However, polymer membranes are limited by their poor resistance to pollution, poor chemical and thermal stability, and, in particular, by the problem of 
maintaining a balance between vapor permeability and selectivity. Thus, the development of new polymer membranes has become an urgent task.

Pervaporation membranes are promising new options for use as polyurethanes [21-31]. The selectivity and productivity of PU membranes are influenced by the chemical and physical structure of membrane materials, particularly the ratio between soft and hard segments and the degree of crosslinking. Nevertheless, few publications are devoted to the use of PU membranes for the pervaporation separation of isopropanol/water mixtures $[21,22,25,26]$. In this way, the effect of the $\mathrm{NCO} / \mathrm{OH}$ ratio on the characteristics and selectivity of polyurethane membranes during the pervaporation separation of isopropanol/water and ethanol/water mixtures was investigated [21]. Polyurethane membranes with a thickness of 90-100 $\mu \mathrm{m}$ were obtained in two stages. First, hydroxyl-terminated polybutadiene (HTPB) was polymerized with 4,4-dicyclohexylmethane diisocyanate $\left(\mathrm{H}_{12} \mathrm{MDI}\right)$ with terminal -NCO groups. Then, upon reaching the theoretically calculated value of the -NCO groups, the polymer chain was extended with 1,4-butanediol (1,4-BD). The authors have shown the influence of the $\mathrm{NCO} / \mathrm{OH}$ ratio on the transport properties of $\mathrm{PU}$ membranes. The best pervaporation characteristics during dehydration of isopropanol (10 wt.\% water) were achieved for $\mathrm{NCO} / \mathrm{OH}=1.5$ at a temperature of $30{ }^{\circ} \mathrm{C}\left(320 \mathrm{~g} / \mathrm{m}^{2} \cdot \mathrm{h}\right.$, selectivity-180).

In [22], polyurethanes were modified by immersing untreated PU membranes in a mixture of formic acid and hydrogen peroxide with a molar ratio of 1:1. Further, $90 \mu \mathrm{m}$ thick polyurethane membranes based on $\mathrm{HTPB}, \mathrm{H}_{12} \mathrm{MDI}$, and 1,4-BD were synthesized using the same two-step method. The authors showed that an increase in the time of PU membranes epoxidation leads to improvement in performance during the pervaporation dehydration of isopropanol. The formation of epoxy and ether groups on the membrane surface increases the affinity of isopropanol for the membrane, which is reflected in the separating properties of epoxidized polyurethane membranes. The best pervaporation characteristics during the dehydration of isopropanol (10 wt.\% water) were achieved at a temperature of $25^{\circ} \mathrm{C}\left(1583 \mathrm{~g} / \mathrm{m}^{2} \cdot \mathrm{h}\right.$, selectivity-4.67).

Hydrophilic polyurethanes are most often used in pervaporation processes, but their use is limited by excessive swelling, which leads to a deterioration in mechanical properties and separation characteristics. Tsai et al. [25] proposed increasing the resistance of the polyurethane membrane to solvents and pervaporation characteristics due to spatial crosslinking with methyl methacrylate (MMA). In this work, PU membranes based on HTPB, H12MDI, and 1,4-BD with a thickness of 90-100 $\mu \mathrm{m}$ were synthesized in two stages. Then crosslinking was performed by sequential polymerization at HTPB/MMA ratios (wt. $/$ wt.\% ratio $)=2.0,1.5,1.0,1.5,0.8$, and 0.6., which were designated as IPN1-IPN5, respectively. The best performance $\left(365 \mathrm{~g} / \mathrm{m}^{2} \cdot \mathrm{h}\right)$ and selectivity (212) in comparison with the standard PU in the pervaporation separation of isopropanol (10 wt.\% water) at an operating temperature of $30^{\circ} \mathrm{C}$ was shown by the composition IPN3; this is explained by the fact that the crosslinking of PU with MMA leads to an increase in the intermolecular space and, consequently, to an increase in transport characteristics.

In [26], an efficient polyurethane membrane was developed for the separation of methanol/water, ethanol/water, and isopropanol/water mixtures based on polyethylene glycol (PEG) with different molecular weights and 2,4-toluene diisocyanate. The molecular weight of the polyether has a significant effect on the selectivity and productivity of polyurethane membranes. The developed polyurethane membrane based on PEG-4000 has a good potential for separating an isopropanol/water mixture (20 wt.\% water) at a temperature of $30^{\circ} \mathrm{C}$, demonstrating a productivity of $730 \mathrm{~g} / \mathrm{m}^{2} \cdot \mathrm{h}$ and a selectivity of 13 .

The main disadvantages of existing polyurethane membranes are that it is difficult to maintain a balance between performance and selectivity and low chemical and mechanical stability. Promising for obtaining highly selective and efficient pervaporation membranes are polyurethane ionomers (PUI) [32-39], which can form highly efficient conducting channels for water molecule transport due to the ability of clustering of ionogenic groups.

In $[40,41]$, exhibiting thermosensitive water vapor permeability, porous polyurethane ionomers based on the aminoethers of boric acid were synthesized. In [42,43], polyurethane 
ionomers (AEPA-PPG-PU) were obtained based on aminoethers of ortho-phosphoric acid (AEPA-PPG). It was found that, during the preparation of AEPA-PPG using triethanolamine as a catalyst and a branching center, a branched compound is formed, in which, due to incomplete etherification of $\mathrm{H}_{3} \mathrm{PO}_{4}$ with triethanolamine and polyoxypropylene glycol (PPG), phosphate anions are present and surrounded by protons (Figure 1).

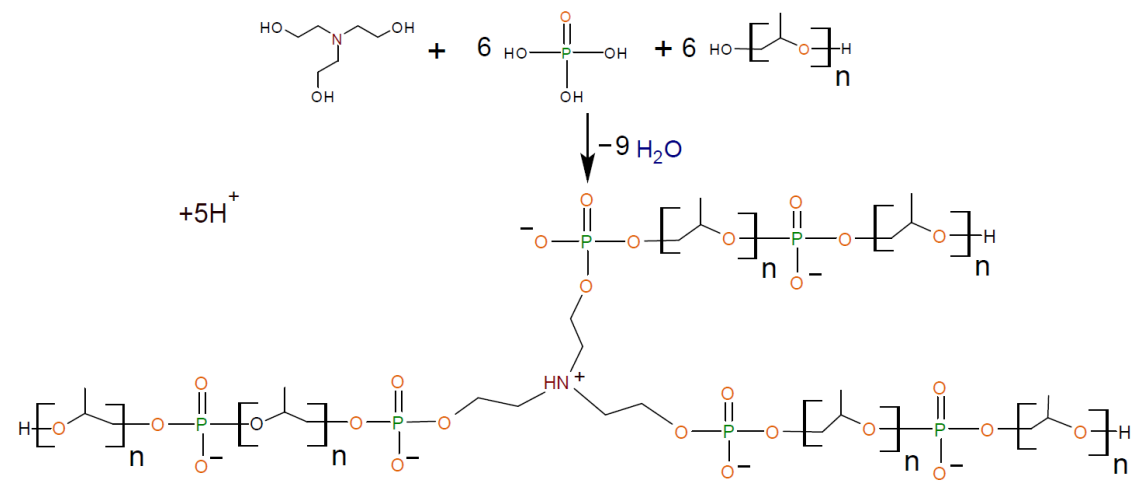

Figure 1. Formation of AEPA-6-PPG.

In the case of the etherification of $\mathrm{H}_{3} \mathrm{PO}_{4}$ using triethylamine as a catalyst, branched compounds (EPA) are also formed (Figure 2), but the $\mathrm{H}_{3} \mathrm{PO}_{4}$ undergoes complete etherification with PPG and the formation of polyphosphate structures. There are practically no ionogenic groups in these compounds.
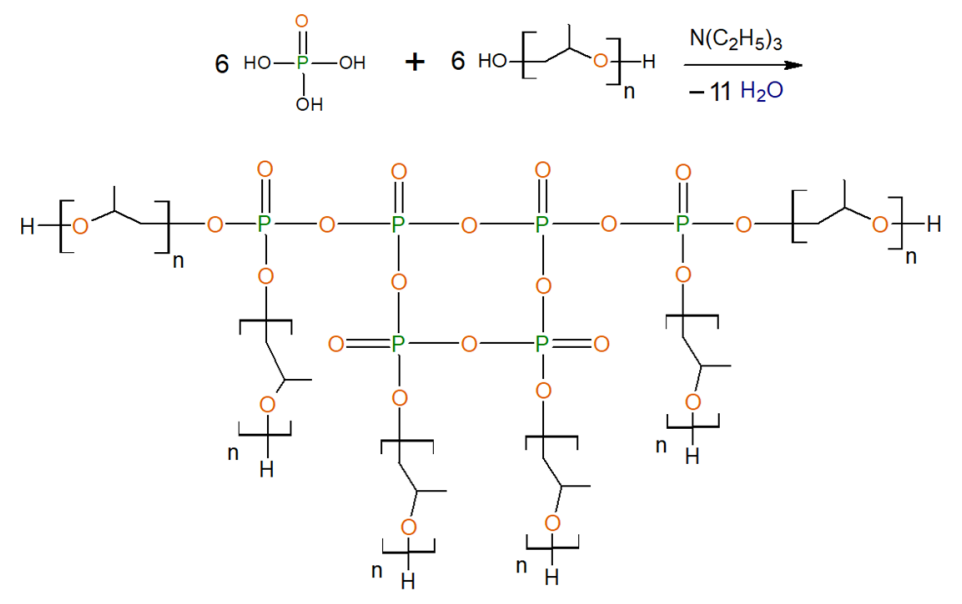

Figure 2. Formation of EPA-6-PPG.

The ionomeric nature of AEPA-PU was the reason for their study as pervaporation membrane materials for the separation of water-alcohol mixtures. To change the content of ionogenic groups in the composition of AEPA and influence the supramolecular organization of aminoethers of ortho-phosphoric acid, polypropylene glycol with $\mathrm{MW}=400$, 1000, 2000 (PPG-400, PPG-1000, PPG-2000), and polyoxyethylene glycol with MM = 400 (PEG-400) were used during synthesis.

\section{Materials and Methods}

\subsection{Solvents and Reagents}

Polyoxypropylene glycol (PPG-400/1000/2000) and polyoxyethylene glycol (PEG400) were purchased from Wanhua Chemical (Beijing, China). Triethanolamine (TEOA) and triethylamine (TEA) were obtained from Ltd. "Component-reaktiv" (Moscow, Russia). Toluene was obtained from Ltd. «Component-reaktiv» (Moscow, Russia). An $85 \%$ aqueous solution of ortho-phosphoric acid (OPA) was purchased from Ltd. «MCDChemicals» (Moscow, Russia). 2-Methylimidazole was purchased from «Acros Organics 
BVBA» (Geel, Belgium). Polyisocyanate "Wannate PM-200" (PIC) was purchased from Kumho Mitsui Chemicals, Inc. (China). Isopropyl alcohol (Propanol-2) was purchased from CJSC «Synthetic Spirit Plant» (Orsk, Russia).

\subsection{Synthetic Procedures}

2.2.1. General Procedure for Synthesis of Amino Ethers of Ortho-Phosphoric Acid (AEPA-PEG-400)

The etherification reaction was carried out in one stage by reacting $\mathrm{H}_{3} \mathrm{PO}_{4}$ with TEOA and PEG-400. To obtain AEPA, triethanolamine, ortho-phosphoric acid, and PPG-1000 were used at their molar ratios [TEOA]:[H$\left.{ }_{3} \mathrm{PO}_{4}\right]$ :[PEG-400] = 1:3:6, 1:4:6, 1:5:6, 1:6:6 (AEPA-3PEG-400, AEPA-4-PEG-400, AEPA-5-PEG-400, and AEPA-6-PEG-400, respectively). The calculated amount of $\mathrm{H}_{3} \mathrm{PO}_{4}$ and PEG-400 was placed in a round-bottom flask, mixed for two minutes, then TEOA was added to the reaction system. Within two hours, the reaction mass was stirred at $\mathrm{T}=80^{\circ} \mathrm{C}$ and a residual pressure of $0.7 \mathrm{kPa}$. The synthesized liquid AEPA-PEG-400 was collected into a stoppered flask. The amount of residual water did not exceed $0.2 \mathrm{wt} . \%$.

2.2.2. General Procedure for Synthesis of Amino Ethers of Ortho-Phosphoric Acid (AEPA-(3 6)-PPG-400/1000/2000)

The etherification reaction was carried out in one stage by reacting OPA with TEOA and PPG. To obtain AEPA, triethanolamine, ortho-phosphoric acid and PPG-400/1000/2000 were used at their molar ratios [TEOA]:[ $\left.\mathrm{H}_{3} \mathrm{PO}_{4}\right]:[\mathrm{PPG}]=1: 3: 6,1: 4: 6,1: 5: 6,1: 6: 6$ (AEPA3-PPG-400/1000/2000, AEPA-4-PPG-400/1000/2000, AEPA-5-PPG-400/1000/2000, and AEPA-6-PPG-400/1000/2000, respectively). The calculated amount of $\mathrm{H}_{3} \mathrm{PO}_{4}$ and PPG was placed in a round-bottom flask, mixed for two minutes, and then TEOA was added to the reaction system. Within two hours, the reaction mass was stirred at $\mathrm{T}=80^{\circ} \mathrm{C}$ and a residual pressure of $0.7 \mathrm{kPa}$. The synthesized liquid AEPA-PPG-400/1000/2000 was collected into a stoppered flask. The amount of residual water did not exceed $0.3 \mathrm{wt} . \%$.

\subsubsection{General Procedure for Synthesis of Ethers of Ortho-Phosphoric Acid} (EPA-(3 6)-PPG-1000)

The etherification reaction was carried out in one stage by reacting $\mathrm{H}_{3} \mathrm{PO}_{4}$ with TEA and PPG. To obtain EPA, triethylamine, ortho-phosphoric acid and PPG-1000 were used at their molar ratios [TEA]:[H $\left.\mathrm{H}_{3} \mathrm{PO}_{4}\right]:[\mathrm{PPG}-1000]=1: 3: 6,1: 4: 6,1: 5: 6,1: 6: 6$ (EPA-3-PPG-1000, EPA-4-PPG-1000, EPA-5-PPG-1000, and EPA-6-PPG-1000, respectively). The calculated amount of $\mathrm{H}_{3} \mathrm{PO}_{4}$ and PPG-1000 was placed in a round-bottom flask, mixed for two minutes, and then TEA was added to the reaction system. Within two hours, the reaction mass was stirred at $\mathrm{T}=80^{\circ} \mathrm{C}$ and a residual pressure of $0.7 \mathrm{kPa}$. The synthesized liquid EPA- $(3 \div 6)$-PPG-1000 was collected into a stoppered flask. The amount of residual water did not exceed $0.3 \mathrm{wt} . \%$.

2.2.4. General Procedure for Synthesis of Polyurethanes Based on Amino Ethers of Ortho-Phosphoric Acid and Ethers of Ortho-Phosphoric Acid (AEPA- $(3 \div$

6)-PPG-1000/2000-PU, EPA-(3 $\div$ 6)-PPG-1000-PU, AEPA-PEG-400-PU).

The synthesized AEPA-( $3 \div 6$ )-PPG-1000/2000, EPA-(3 $\div$ 6)-PPG-1000, and AEPA$(3 \div 6)$-PEG-400 were mixed with PIC in specific ratios (1:1). Then, the solvent (toluene) was added in a certain amount to obtain a urethane-forming reaction system with a certain solute content (SC). Stirring was continued for $5 \mathrm{~min}$ at room temperature and the mixture was cast onto the prepared surfaces to form polyurethane films. After the solvent evaporated, the curing of polyurethanes was carried out for $24 \mathrm{~h}$ at room temperature. After the final curing, the samples were heated for $10 \mathrm{~min}$ at $100{ }^{\circ} \mathrm{C}$ to remove residual solvent. As a result, film materials were obtained under conditions of solute content from 20 to 100 wt. $\%$ (SC $=20 \div 100$ wt. $\%$ ). 


\subsection{Manufacturing of Pervaporation Membranes}

A hydrophilic porous support based on a fluoroplastic-MDK (composite membrane)1,2 (pore size $500 \mathrm{~nm}$, thickness 90 microns, from Vladipor, Russia) —was chosen to prepare the supported membranes with AEPA-PPG-1000-PU and a hydrophilic porous support based on a fluoroplastic-UFFK (ultrafiltration membranes) (pore size $50 \mathrm{~nm}$, thickness 90 microns, from Vladipor, Russia) — was chosen to prepare the supported membranes with AEPA-PEG-400-PU. The main reason for using different substrates is that AEPA and polyurethanes synthesized from them are obtained from different natures of polyether and have different wetting properties.

To manufacture the composite membrane, the selective layer was applied to the substrate using a cylindrical applicator KAU 1 (Constanta, St. Petersburg, Russia). The substrate was fixed to a glass plate to prevent any folding or twisting. The thickness of the applied selective layer was set using guides of constant thickness fixed at the edges of the substrate, on the surface of which the applicator was manually moved. The selective layer was cured at room conditions for $24 \mathrm{~h}$.

\subsection{Fourier Transform Infrared Spectroscopy Analysis (FTIR)}

The FTIR spectra of the products were recorded on the Nicolet iS20 FT-IR spectrometer (Thermo Fisher Scientific, Waltham, MA, USA) using the attenuated total reflection technique. The spectra were acquired by accumulating 64 scans at a spectral resolution of $4 \mathrm{~cm}^{-1}$ in an absorbance mode from 3600 to $600 \mathrm{~cm}^{-1}$.

\subsection{Viscosity and Density Measurements}

The dynamic viscosity of the samples was determined at the $\mathrm{T}=20^{\circ} \mathrm{C}$ and atmospheric pressure on an SVM 3000 Stabinger Viscometer (Anton Paar, Austria), with a systematic error of $\pm 0.35 \%$ of the measured value. At the same time, the density of the samples was determined with a systematic error of $0.0005 \mathrm{~g} / \mathrm{cm}^{3}$.

\subsection{Measurements of the Surface Tension}

The droplet counting method was used to determine the surface tension $(\sigma)$. The basis of the calculations is the equation, where the weight of the drop that comes off the pipette is proportional to the surface tension of the fluid and the radius of the pipette (R): $\mathrm{m}=2 \pi \cdot \mathrm{R} \cdot \sigma / \mathrm{g}$, where: $\mathrm{g}$ is the acceleration of gravity; $m$ is the drop mass of the test liquid. Following this equation: $\sigma=\mathrm{mg} / 2 \pi \mathrm{R}$. Further, according to the obtained results, the surface tension $(\sigma)$ was constructed from the characteristic curve of the concentration $(C)$.

\subsection{Tensile Stress-Strain Measurements}

Tensile stress-strain measurements were obtained from the film samples of size $40 \mathrm{~mm} \times 15 \mathrm{~mm}$ with Universal Testing Machine Inspekt mini (Hegewald\&PeschkeMeßund Prüftechnik GmbH, Nossen, Germany) at $293 \pm 2 \mathrm{~K}, 1 \mathrm{kN}$. The crosshead speed was set at $50 \mathrm{~mm} / \mathrm{min}$, and the test continued until sample failure. Minima of five tests were analyzed for each sample, and the average values were reported.

\subsection{Thermomechanical Analysis (TMA)}

The thermomechanical curves of polymer samples were obtained using TMA $402 \mathrm{~F}$ (Netzsch, Selb, Germany) thermomechanical analyzer in the compression mode. The sample thickness was $2 \mathrm{~mm}$, and the rate of heating was $3{ }^{\circ} \mathrm{C} / \mathrm{min}$ from $-50{ }^{\circ} \mathrm{C}$ to $350{ }^{\circ} \mathrm{C}$ in the static mode. The load was $2 \mathrm{~N}$.

\subsection{Mechanical Loss Tangent Measurements (MLT)}

The MLT curves of polymer samples were taken using the dynamic mechanical analyzer DMA 242 (Netzsch, Selb, Germany) in the mode of oscillating load. Force and stress-stain correspondence was calibrated using a standard mass. The thickness of the sample was $2 \mathrm{~mm}$. Viscoelastic properties were measured under nitrogen. The samples 
were heated from $-50{ }^{\circ} \mathrm{C}$ to $350{ }^{\circ} \mathrm{C}$ at the rate of $3{ }^{\circ} \mathrm{C} / \mathrm{min}$ and a frequency of $1 \mathrm{~Hz}$. The mechanical loss tangent was defined as the ratio of the viscosity modulus $G^{\prime \prime}$ to the elasticity modulus $\mathrm{G}^{\prime}$.

\subsection{Thermal Gravimetric Analysis (TGA)}

TGA was performed using STA-600 TGA-DTA combined thermal analyzer (Perkin Elmer, Waltham, MA, USA). The samples $(0.1 \mathrm{~g})$ were loaded in alumina pans and heated from 30 to $750{ }^{\circ} \mathrm{C}$ at a rate of $5{ }^{\circ} \mathrm{C} / \mathrm{min}$ in a nitrogen atmosphere.

\subsection{The Densitometer}

The density of the composites was determined on an H-300S (Hildebrand, Oberboihingen, Germany) densitometer with an ultra-high resolution of $0.001 \mathrm{~g} / \mathrm{cm}^{3}$.

\subsection{Water Adsorption}

Water adsorption was determined by the gravimetric method. A sample of a certain size was cut out from the obtained polymer. The resulting sample was weighed on an analytical balance. The measuring cup loaded with distilled water, and then the sample was placed in water and fixed. After a specified amount of time, the samples were removed, the remaining water from the surface was removed using filter paper, and the sample was weighed. Water adsorption (B) is calculated as a percentage using the formula:

$$
B=(m s-m) / m
$$

where: $\mathrm{m}$ - the mass of the sample before the test, g; ms-the mass of the sample after the test. For the result, the arithmetic average of the results of the 5 tests was used.

\subsection{Water Vapor Permeability (WVP) Measurements}

WVP was measured according to the ASTM method of E 96-80B. Round mouth cylindrical glass cups with a diameter of $50 \mathrm{~mm}$ and a height of $70 \mathrm{~mm}$ were filled with deionized water. Membranes were placed over the top of the cups and secured the perfect sealing between the cup and the membranes. The gaps between the membrane and the water surface were about $15 \mathrm{~mm}$. The cups were placed in a constant temperature chamber at the temperature $22{ }^{\circ} \mathrm{C}$ and $40{ }^{\circ} \mathrm{C}$. The humidity in the chamber was $90 \%$. The weight losses after $24 \mathrm{~h}$ were measured. The result of water vapor permeability was calculated by the following formula:

$$
W V P=\frac{G}{t A}
$$

where $G$ is the weight change in grams; $t$ is the duration of the test in hours; $A$ is the test area in $\mathrm{m}^{2}$.

During all WVP measurements, the air surrounding the membranes had a constant temperature and relative humidity of $90 \%$. Sample thicknesses for all measurements were in the range of approximately 80 microns. On average, three different readings were used for each WVP measurement, which were expressed in units of $\mathrm{g} / \mathrm{m}^{2} 24 \mathrm{~h}$.

\subsection{Pervaporation Processes}

Experimental studies were carried out for an isopropanol/water mixture at a concentration of $85 \mathrm{wt} . \%$ isopropanol and $15 \mathrm{wt} . \%$ water in a model mixture, at a temperature of $60{ }^{\circ} \mathrm{C} / 40{ }^{\circ} \mathrm{C}$, and a vacuum depth of $20 \mathrm{~mm} \mathrm{Hg}$. Art. A model mixture of isopropanol/water was prepared from demineralized water (specific conductivity of $5 \mu \mathrm{S} / \mathrm{cm}$ ) obtained on an Osmodemi 12 setup (ERREDUE S.P.A, Livorno, Italy) and dehydrated isopropanol with a main component content of $99.8 \mathrm{wt} . \%$. A scheme of the experimental pervaporation unit used to study the separation characteristics of polymer membranes is shown in Figure 3. 


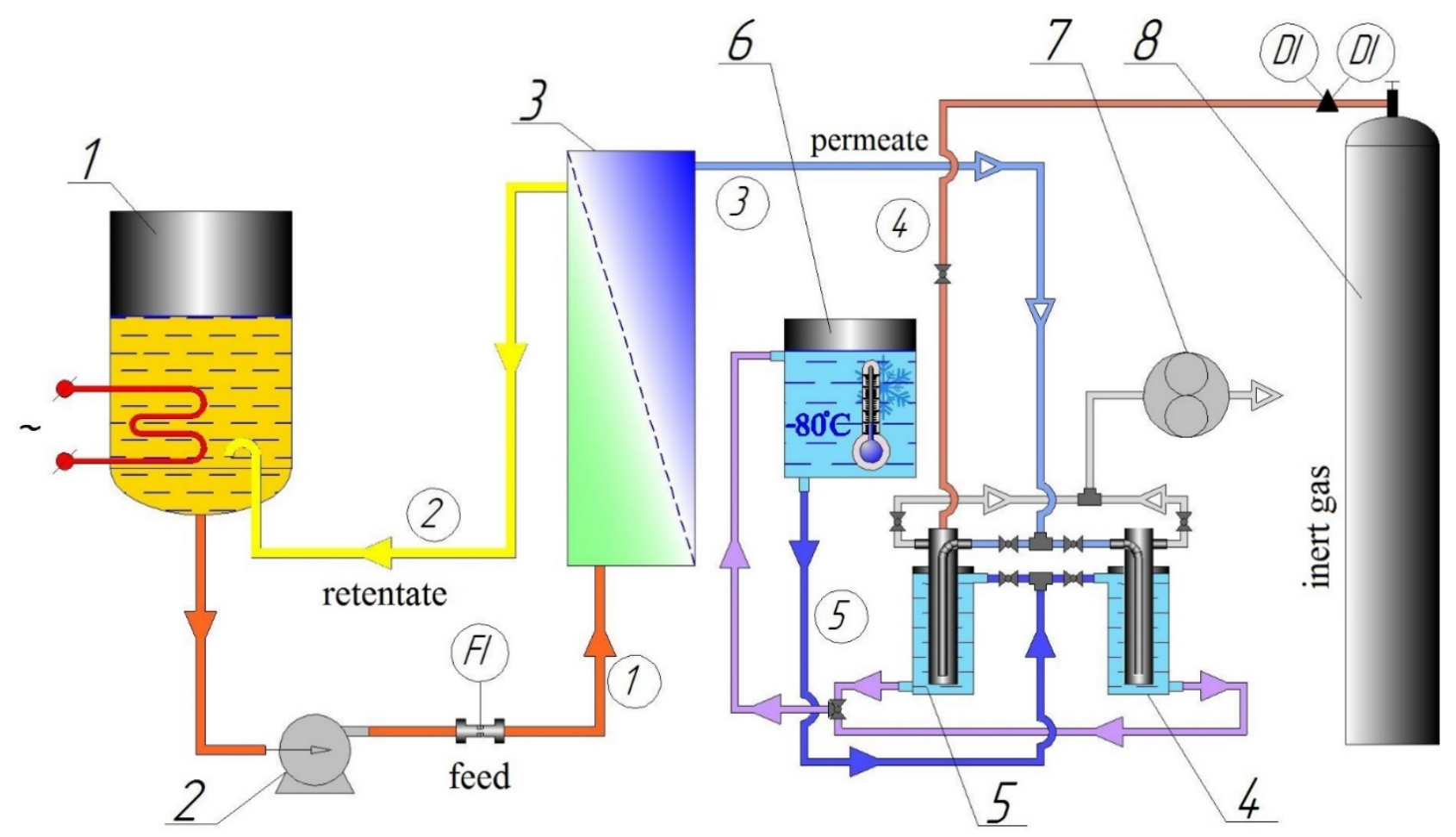

Figure 3. Scheme of the experimental pervaporation unit: 1-raw material capacity; 2-feed pump; 3-cell for membranes; 4, 5—cold traps; 6-cryostat; 7-vacuum pump; 8-inert gas cylinder.

The plant consists of two main parts - raw material and vacuum (permeate) part. In the raw part, with the help of a pump through lines 1 and 2 (line numbers are enclosed in a circle), the raw material is circulated between the raw material tank and the membrane cell. The pressure in the raw material is close to atmospheric. A thermal cable is fixed on the wall of the raw material tank to maintain the set temperature of the experiment. In the cell for membranes, the raw material moves in a spiral along the surface of the membrane at a speed of more than $2 \mathrm{~m} / \mathrm{s}$; this makes it possible to reduce the concentration polarization. The vacuum under the membrane is created using a membrane-type vacuum pump. From the casing of the membrane module, permeate vapors, moving along line 3 , fall into cold flow traps 4 or 5 , which are cooled by a refrigerant with a temperature of $-80^{\circ} \mathrm{C}$ supplied through line 5 from the cryostat. Cold trap 4 is a prelaunch one and is used to bring the installation to a given mode; the experiments themselves were carried out on trap 5, which is a measuring one. After the end of the experiment, measuring trap 5 was cut off from line 3 and the line of connection with vacuum pump 6 . To equalize the pressure and prevent moisture condensation from the air, nitrogen is supplied to the trap 5 through pipeline 4 .

The composition permeate flux was analyzed using gas chromatograph Crystal-2000M (JSC SDO «Chromatec», Yoshkar-Ola, Russia), which was equipped with a thermal conductivity detector and with a capillary column HP-FFAP $50 \mathrm{~m} \times 0.53 \mathrm{~mm} \times 0.25 \mu \mathrm{m}$ (Agilent Technologies, Inc., Santa Clara, CA, USA). Helium was the carrier gas, with a total of $20 \mathrm{~mL} / \mathrm{min}$. Samples of $1 \mu \mathrm{L}$ were injected with a liquid autosampler AS-2M SP (JSC SDO «Chromatec») into the chromatograph. The injection port temperature, detector, and column were equal to $220^{\circ} \mathrm{C}, 250{ }^{\circ} \mathrm{C}$, and $77^{\circ} \mathrm{C}$, respectively. Samples were analyzed using the Chromatec Analytic software (version 2.6.014, JSC SDO «Chromatec)).

The values of the total permeate flux J, the separation factor $\alpha$, and the pervaporation separation index PSI were determined from the measurement data using the following expressions:

$$
\mathrm{J}=\frac{\mathrm{m}^{\mathrm{p}}}{\mathrm{F} \Delta \mathrm{t}} \alpha=\frac{\mathrm{x}_{\mathrm{A}}^{\mathrm{P}} / \mathrm{x}_{\mathrm{A}}^{\mathrm{F}}}{\mathrm{x}_{\mathrm{B}}^{\mathrm{P}} / \mathrm{x}_{\mathrm{B}}^{\mathrm{F}}} \alpha=\frac{\mathrm{x}_{\mathrm{A}}^{\mathrm{P}} / \mathrm{x}_{\mathrm{A}}^{\mathrm{F}}}{\mathrm{x}_{\mathrm{B}}^{\mathrm{P}} / \mathrm{x}_{\mathrm{B}}^{\mathrm{F}}}
$$


where $\mathrm{m}^{\mathrm{p}}$ is the mass of the permeate, $\mathrm{kg}$, collected over the time interval $\Delta \mathrm{t}, \mathrm{h} . ; \mathrm{F}$ is the membrane surface area $\mathrm{M}^{2} ; \mathrm{x}_{\mathrm{A}}^{\mathrm{P}}$ and $\mathrm{x}_{\mathrm{B}}^{\mathrm{P}}$ are the mass concentrations of the components $\mathrm{A}$ (isopropanol) and $\mathrm{B}$ (water) in the permeate, respectively, wt.\%; $\mathrm{x}_{\mathrm{A}}^{\mathrm{F}}$ and $\mathrm{x}_{\mathrm{B}}^{\mathrm{F}}$ are mass concentrations of components A and B in retant (raw material), respectively, wt.\%.

\section{Results}

3.1. Membranes Based on AEPA-PPG-1000/2000-PU

\subsubsection{Water vapor permeability of AEPA-PPG-1000/2000-PU}

Film samples of AEPA-PPG-1000-PU were obtained both by casting them from solutions of the urethane-forming system and directly from the SC $=100$ wt. $\%$, i.e., without using a solvent.

The completeness of the terminal hydroxyl groups' interaction of the AEPA with the isocyanate groups of the PIC can be judged by the FTIR spectra analysis. The spectra do not show the characteristic bands at $2275 \mathrm{~cm}^{-1}$ of NCO groups (Figure 4).

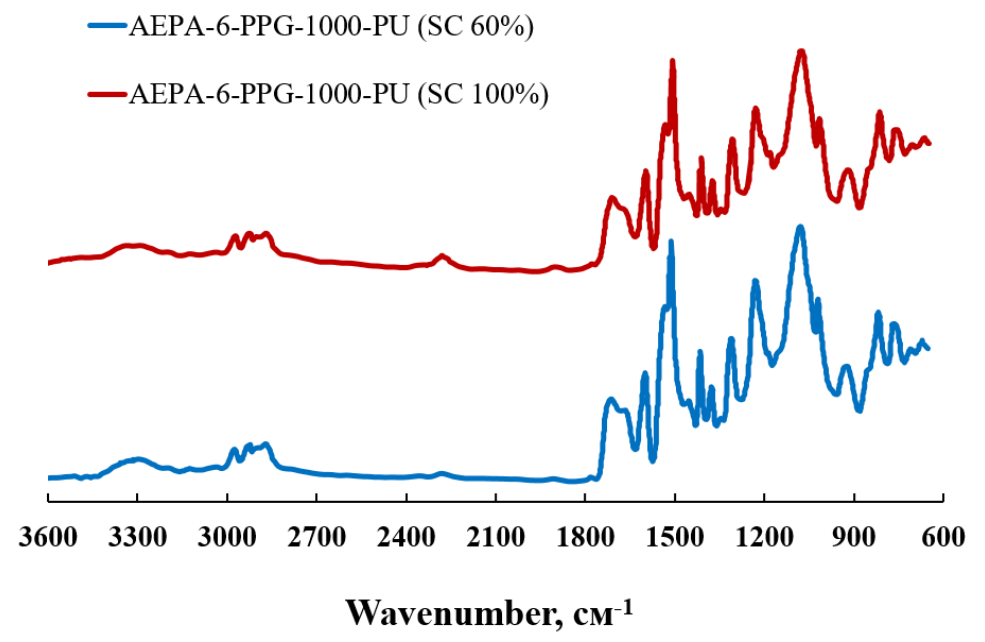

Figure 4. FTIR spectra of AEPA-6-PPG-1000-PU obtained at different SC.

It was found that the solute content (SC) in the solutions of the urethane-forming system has a significant effect on the water vapor permeability of the resulting film materials. AEPA-6-PPG-1000-PU obtained at SC $=60 \mathrm{wt} . \%$ exhibit a low degree of water adsorption (1.2 wt.\%) and low vapor permeability (Figure 5). Starting with an SC content of $70 \mathrm{wt} . \%$, the water vapor permeability begins to increase markedly, increasing 2.5 times at SC $=100 \mathrm{wt} . \%$. At the same time, an increase in water adsorption (3.3 wt.\%) of AEPA-6-PPG-1000-PU is observed.

Due to the fact that the highest values of water adsorption and water vapor permeability are observed at SC $=100 \mathrm{wt} . \%$ in the solutions of the urethane-forming system, further studies of vapor permeability and pervaporation characteristics were carried out for polyurethanes obtained at SC $=100 \mathrm{wt} . \%$.

The water vapor permeability of the samples is significantly influenced by the content of $\mathrm{H}_{3} \mathrm{PO}_{4}$ in the AEPA-PPG-1000-PU composition (Figure 6). An increase in the content of $\mathrm{H}_{3} \mathrm{PO}_{4}$ in the composition of AEPA-PPG-1000 and, accordingly, in AEPA-PPG-1000-PU leads to an increase in the content of ionogenic groups in the composition of AEPA-PPG1000-PU. 


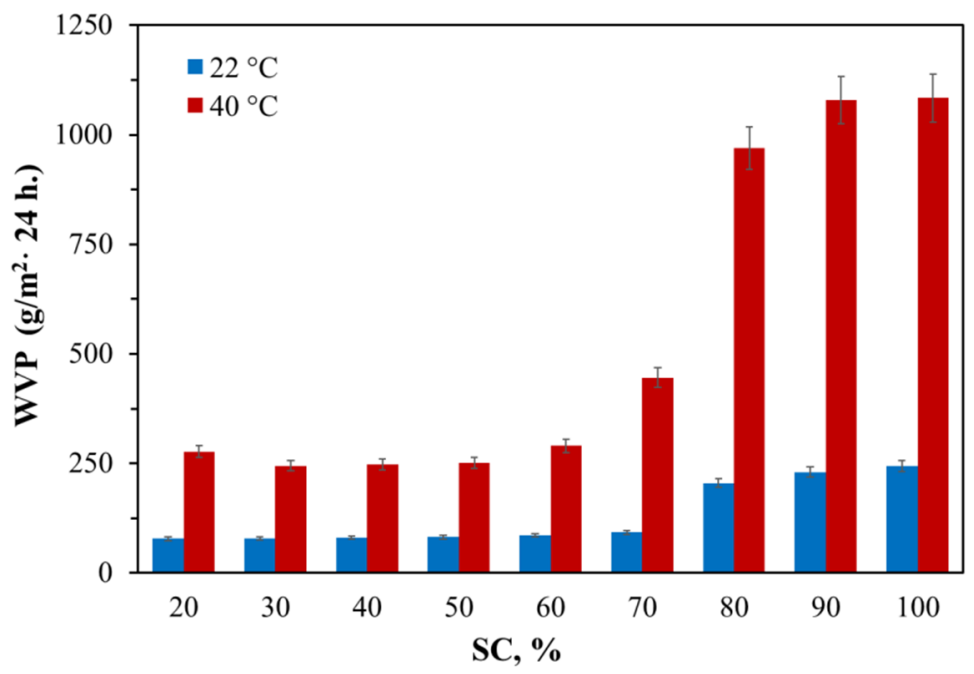

Figure 5. Water vapor permeability coefficients for AEPA-6-PPG-1000-PU obtained at different SC.

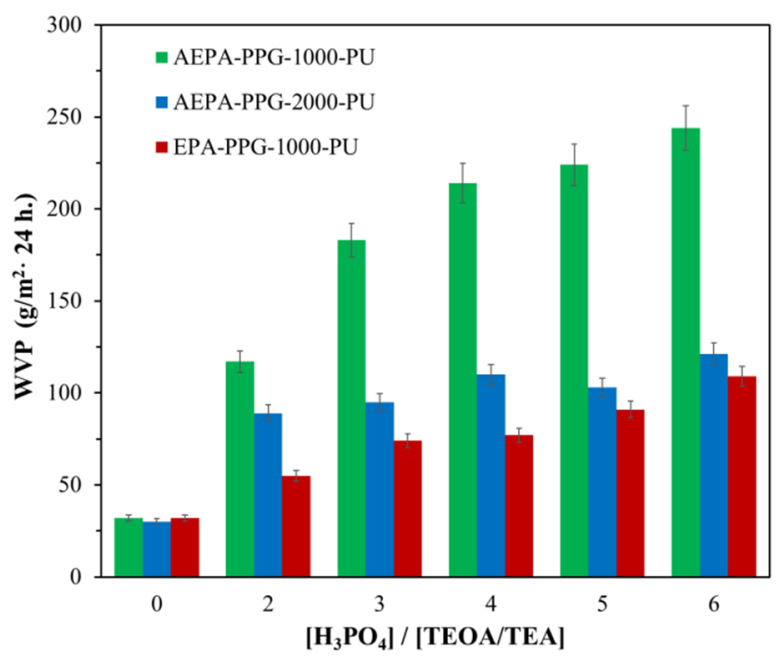

(a)

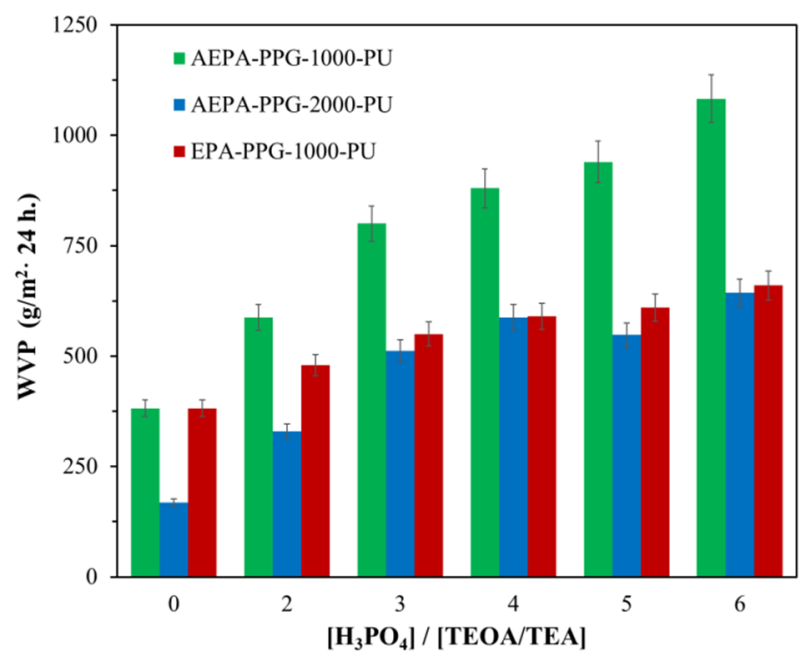

(b)

Figure 6. Dependences of the water vapor permeability coefficients at $22{ }^{\circ} \mathrm{C}(\mathbf{a})$ and $40{ }^{\circ} \mathrm{C}(\mathbf{b})$ on the molar ratio of $\left[\mathrm{H}_{3} \mathrm{PO}_{4}\right] /[\mathrm{TEOA}]$ for AEPA-PPG-1000/2000-PU and $\left[\mathrm{H}_{3} \mathrm{PO}_{4}\right] /[\mathrm{TEA}]$ for EPA-PPG-1000-PU, obtained at SC = $100 \mathrm{wt} . \%$.

To substantiate the key role of ionogenic groups in the formation of water vapor permeability of AEPA-PPG-1000-PU, polyurethanes of non-ionic nature (EPC-PPG-1000-PU) obtained based on EPA were studied. According to Figure 6, the water vapor permeability of EPA-PPG-1000-PU also increases with an increase of $\mathrm{H}_{3} \mathrm{PO}_{4}$ content in the composition of EPA. However, the values of the water vapor permeability coefficient themselves turned out to be more than two times lower in comparison with the samples of AEPA-PPG-1000PU. It should be noted that the water adsorption values for EPA-6-PPG-1000-PU obtained at SC $=100 \mathrm{wt}$. $\%$ are slightly lower (2.1 wt.\%) in comparison with AEPA-6-PPG-1000-PU obtained under similar conditions (3.3 wt.\%).

In order to confirm the decisive role of the supramolecular structure on the vapor permeability of thin films of AEPA-PPG-1000-PU, polyurethanes were synthesized using PPG with $\mathrm{MW}=2000$ (AEPA-PPG-2000-PU). The premise for this approach was the assumption that a higher molecular weight of PPG-2000 molecules in comparison with PPG-1000 entails a corresponding decrease in the content of ionomeric structures in AEPAPPG-2000-PU in comparison with AEPA-PPG-1000-PU. According to Figure 6, an increase in the molecular weight of PPG led to a decrease in the water vapor permeability coefficient 
for AEPA-PPG-2000-PU relative to AEPA-PPG-1000-PU. The water adsorption values for AEPA-5-PPG-2000-PU and AEPA-6-PPG-2000-PU remained low (2.1 and 1.9 wt.\%).

\subsubsection{Surface-Active Properties of AEPA-PPG- $1000 / 2000$}

In connection with the results obtained, comparative studies of the surface tension of AEPA-PPG-1000 and AEPA-PPG-2000 were carried out. According to Figure 7a, the critical micelle concentration and the surface tension of PPG-2000 turned out to be lower than these values measured for PPG-1000. Nevertheless, the regularities of changes in surface tension for AEPA-PPG-2000 and AEPA-PPG-1000 are similar in manifestation, i.e., the structure of AEPA-PPG-2000, similarly to AEPA, is ionomeric, the only difference is in the length of the polyether branches.

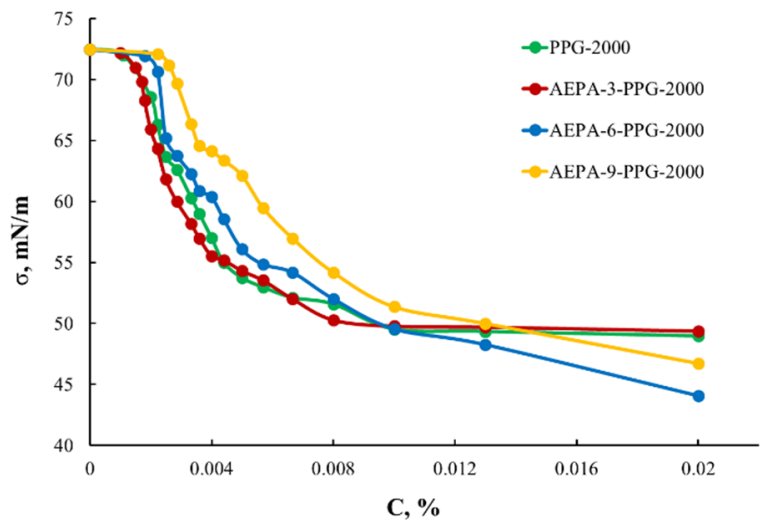

(a)

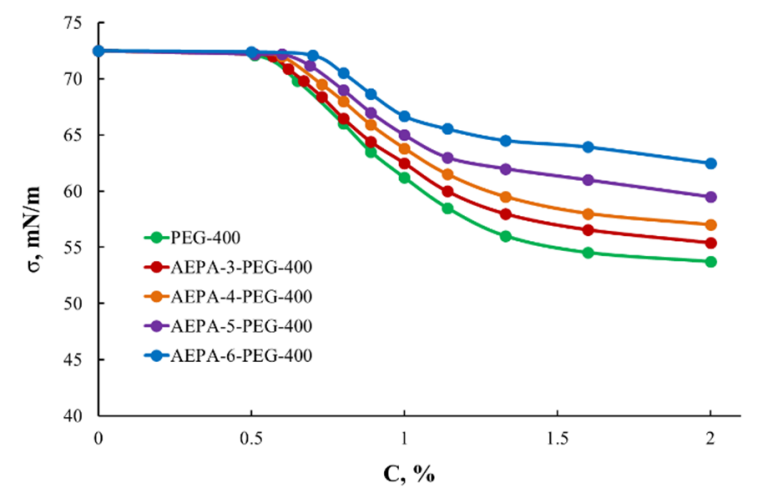

(c)

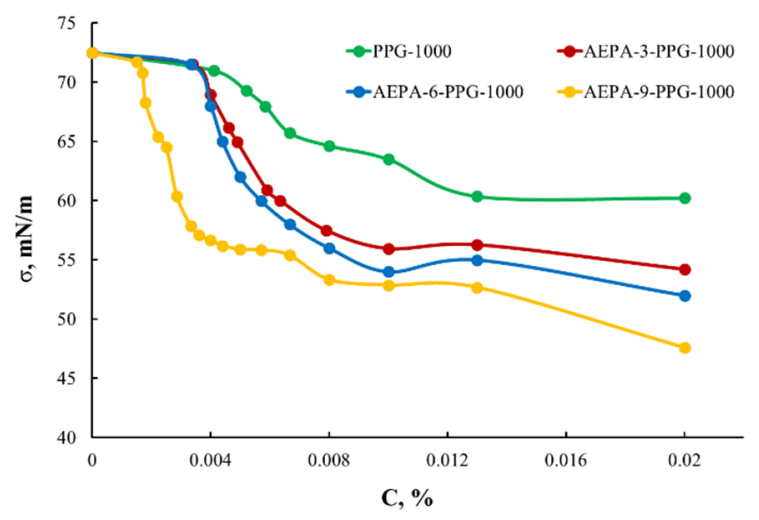

(b)

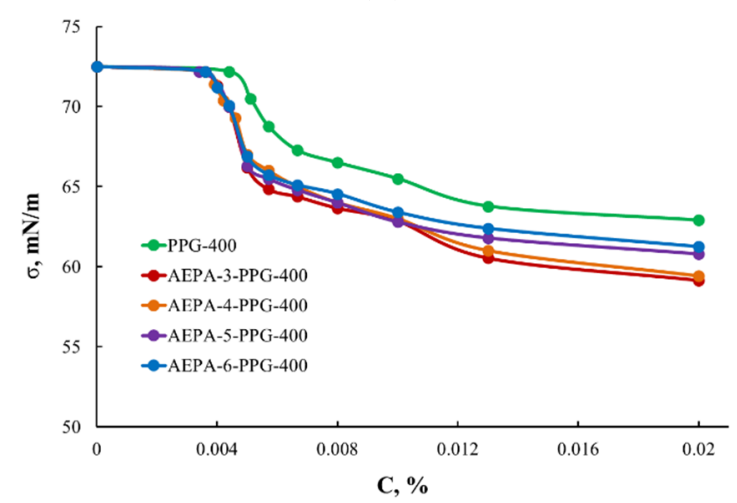

(d)

Figure 7. Surface tension isotherms for AEPA-PPG-2000 and PPG-2000 (a); AEPA-PPG-1000 and PPG-1000 (b); AEPA-PEG400 and PEG-400 (c); AEPA-PPG-400 and PPG-400 (d).

3.1.3. Study of AEPA-PPG-1000-PU as Pervaporation Membranes for the Separation of Isopropanol/Water Mixtures

Studies of the regularities of the vapor permeability coefficient changes made it possible to establish that the WVP values noticeably increase both with an increase in the content of ionogenic groups in the composition of AEPA-PPG-1000-PU and with an increase in the content of SC in the urethane-forming system. AEPA-PPG-1000-PU, obtained at SC $=100 \mathrm{wt} . \%$, was used to manufacture pervaporation membranes for isopropanol dehydration. According to the results shown in Table 1, polyurethane membranes exhibit high membrane performance, which increases with an increase in the content of ionogenic groups in the composition of AEPA-PPG-1000-PU. 
Table 1. Isopropanol dehydration using pervaporation membranes based on AEPA-PPG-1000-PU and AEPA-PEG-PU, obtained at SC = $100 \mathrm{wt}$.\%. Isopropanol in the feed, $85 \mathrm{wt} . \%$.

\begin{tabular}{|c|c|c|c|c|}
\hline Polyurethane & Water in Permeate, wt.\% & Flux, $\mathrm{g} / \mathrm{m}^{2} \cdot \mathrm{h}$ & Separation Factor & PSI, $g / \mathrm{m}^{2} \cdot h$ \\
\hline \multicolumn{5}{|c|}{ Feed temperature, $40^{\circ} \mathrm{C}$} \\
\hline AEPA-3-PPG-1000-PU & 84.4 & 880 & 51 & 44 \\
\hline AEPA-4-PPG-1000-PU & 83.2 & 1021 & 49 & 49 \\
\hline AEPA-5-PPG-1000-PU & 82.8 & 1145 & 52 & 58.4 \\
\hline AEPA-6-PPG-1000-PU & 80.9 & 1250 & 45 & 52.8 \\
\hline AEPA-3-PEG-400-PU & 96.4 & 653 & 151 & 98.0 \\
\hline AEPA-4-PEG-400-PU & 96.3 & 805 & 148 & 118.3 \\
\hline AEPA-5-PEG-400-PU & 90.9 & 2039 & 56 & 112.2 \\
\hline AEPA-6-PEG-400-PU & 90.1 & 1580 & 65 & 101.1 \\
\hline \multicolumn{5}{|c|}{ Feed temperature, $60^{\circ} \mathrm{C}$} \\
\hline AEPA-3-PPG-1000-PU & 83.0 & 1800 & 28 & 48.6 \\
\hline AEPA-4-PPG-1000-PU & 82.0 & 2551 & 26 & 56.3 \\
\hline AEPA-5-PPG-1000-PU & 81.1 & 2655 & 24 & 74.3 \\
\hline AEPA-6-PPG-1000-PU & 79.1 & 2853 & 21 & 57.1 \\
\hline AEPA-3-PEG-400-PU & 92.7 & 1859 & 72 & 132.0 \\
\hline AEPA-4-PEG-400-PU & 92.6 & 2298 & 71 & 161.0 \\
\hline AEPA-5-PEG-400-PU & 90.5 & 3734 & 54 & 197.9 \\
\hline AEPA-6-PEG-400-PU & 89.2 & 2624 & 62 & 160.0 \\
\hline
\end{tabular}

In order to evaluate the advantages of the obtained pervaporation membranes, in the introductory part of this article, the indicators of the separation efficiency of the isopropanol/water mixture of the currently known pervaporation polyurethane membranes were given. So, in [21], polyurethanes were obtained on the basis of oligobutadienediol, 4,4-dicyclohexylmethane diisocyanate, and 1,4-butanediol. The highest flow values for the isopropanol/water mixture was $320 \mathrm{~g} / \mathrm{m}^{2} \cdot \mathrm{h}$, and the selectivity was 180 . In this case, testing was carried out at an isopropanol content of $90 \mathrm{wt} . \%$ and operating temperature of $30^{\circ} \mathrm{C}$. In [22], epoxidized polyurethane membranes were synthesized on the basis of oligobutadienediol, 4,4-dicyclohexylmethanediisocyanate, and 1,4-butanediol. The highest productivity of epoxidized polyurethane membranes for an isopropanol/water mixture at $25^{\circ} \mathrm{C}$ was $1583 \mathrm{~g} / \mathrm{m}^{2} \cdot \mathrm{h}$, and the selectivity was 4.67 . In [25], pervaporation polyurethane membranes with an interpenetrating polymer network, obtained on the basis of oligobutadienediol and polymethyl methacrylate, were studied. When separating a $90 \mathrm{wt} . \%$ isopropanol solution, the highest productivity of such membranes was $365 \mathrm{~g} / \mathrm{m}^{2} \cdot \mathrm{h}$, and the selectivity was 212 at an operating temperature of $30^{\circ} \mathrm{C}$. In [26], the authors investigated a number of polyether urethane membranes based on polyoxyethylene glycol and 2,4-toluene diisocyanate by the pervaporation method for isopropanol/water mixtures. The authors stated that the selectivity and performance of polyurethane membranes are significantly influenced by the molecular weight of the polyether. A membrane based on PEG-4000 showed the highest efficiency in separating of isopropanol/water mixture. At an operating temperature of $30^{\circ} \mathrm{C}$ and water content of $80 \mathrm{wt} . \%$ in the separated mixture, the flow values were $481.9 \mathrm{~g} / \mathrm{m}^{2} \cdot \mathrm{h}$, and the selectivity was 68.7 . At a water content of $20 \mathrm{wt} . \%$ in the separated mixture, the flow was $730 \mathrm{~g} / \mathrm{m}^{2} \cdot \mathrm{h}$, and the selectivity was 13 .

Thus, compared to the pervaporation separation index of isopropanol/water mixture with the known analog polyurethane membranes, the membranes obtained from AEPAPEG have high values. 


\subsubsection{Thermogravimetric Analysis of AEPA-PU}

The detected difference in the regularities of changes in the conditions for the film material formation on the molecular structure of AEPA-PU also affects their thermal behavior. Thus, for AEPA-PU obtained at SC $=60 \mathrm{wt} . \%$, the onset of weight loss in the air is observed at a temperature that, on average, is $7^{\circ} \mathrm{C}$ higher than the temperature of the onset of weight loss for AEPA-PU obtained from the SC $=100 \mathrm{wt} . \%$ (Table 2). At the same time, the temperature corresponding to $50 \%$ weight loss $\left(\mathrm{T}_{50 \%}\right)$ for AEPA-PU obtained from the SC $=100 \mathrm{wt} . \%$ exceeds by $10-30{ }^{\circ} \mathrm{C}$ that for AEPA-PU obtained at SC $=60 \mathrm{wt} . \%$. For AEPA-PU obtained from the SC $=100 \mathrm{wt} . \%$, a higher (by $2 \mathrm{wt} . \%$ ) char residue content is also observed. An increase in the sample's thermal stability in the high-temperature region can be a consequence of the ionomeric organophosphorus component clustering Table 2.

Table 2. Characteristics of the thermal stability of AEPA-PPG-1000-PU under air atmosphere.

\begin{tabular}{ccccc}
\hline Polyurethane & $\mathbf{T}_{\mathbf{5} \%}\left({ }^{\circ} \mathbf{C}\right)$ & $\mathbf{T}_{\mathbf{1 0} \%}\left({ }^{\circ} \mathbf{C}\right)$ & $\mathbf{T}_{\mathbf{5 0} \%}\left({ }^{\circ} \mathbf{C}\right)$ & $\begin{array}{c}\text { Coke Content at } \mathbf{6 0 0}{ }^{\circ} \mathbf{C}, \\
\mathbf{w t} \%\end{array}$ \\
\hline AEPA-3-PPG-1000-PU & $278 / 271$ & $292 / 284$ & $369 / 394$ & $5 / 2$ \\
AEPA-4-PPG-1000-PU & $275 / 266$ & $292 / 283$ & $381 / 414$ & $3.5 / 6$ \\
AEPA-5-PPG-1000-PU & $277 / 268$ & $293 / 282$ & $378 / 410$ & $4 / 6$ \\
AEPA-6-PPG-1000-PU & $280 / 263$ & $294 / 284$ & $383 / 401$ & $5 / 6$ \\
\hline
\end{tabular}

* The values in the numerator refer to $\mathrm{SC}=60 \mathrm{wt} . \%$, and the values in the denominator refer to $\mathrm{SC}=100 \mathrm{wt} . \%$.

The fact that an increase in the SC content to $100 \mathrm{wt} . \%$ leads to the processes of clustering of the organophosphorus ionomer component in AEPA-PU is also confirmed by the data of TGA analysis carried out in an inert medium (Table 3). Thus, AEPA-PU obtained at $\mathrm{SC}=100 \mathrm{wt} . \%$ turned out to be significantly more heat-resistant in comparison with AEPA-PU obtained at $\mathrm{SC}=60 \mathrm{wt} . \%$. The assumption about the clustering of ionomeric organophosphorus structures in AEPA-PU is also confirmed by the TGA data obtained for EPA-PU, which do not contain ionogenic groups (Table 3). In this case, an increase in SC from 60 to $100 \mathrm{wt}$.\% during the production of EPA-PU does not lead to noticeable changes in the thermal stability of the samples.

Table 3. Characteristics of the thermal stability of AEPA-PPG-1000-PU and EPA-PGG-1000-PU under nitrogen atmosphere.

\begin{tabular}{ccccc}
\hline Polyurethane & $\mathbf{T}_{\mathbf{5}} \mathbf{\%}\left({ }^{\circ} \mathbf{C}\right)$ & $\mathbf{T}_{\mathbf{1 0}} \mathbf{\%}\left({ }^{\circ} \mathbf{C}\right)$ & $\mathbf{T}_{\mathbf{5 0}} \mathbf{\%}\left({ }^{\circ} \mathbf{C}\right)$ & $\begin{array}{c}\text { Coke Content at } \mathbf{6 0 0}{ }^{\circ} \mathbf{C}, \\
\mathbf{w t} . \%\end{array}$ \\
\hline AEPA-3-PPG-1000-PU & $308 / 296$ & $322 / 313$ & $362 / 364$ & $17 / 20$ \\
AEPA-4-PPG-1000-PU & $235 / 295$ & $268 / 309$ & $310 / 352$ & $16 / 19.1$ \\
AEPA-5-PPG-1000-PU & $220 / 291$ & $243 / 308$ & $300 / 349$ & $14 / 18.5$ \\
AEPA-6-PPG-1000-PU & $275 / 294$ & $300 / 312$ & $350 / 350$ & $15 / 16$ \\
EPA-3-PPG-1000-PU & $300 / 298$ & $317 / 318$ & $365 / 372$ & $18 / 26$ \\
EPA-4-PPG-1000-PU & $295 / 298$ & $311 / 316$ & $355 / 368$ & $17 / 21$ \\
EPA-5-PPG-1000-PU & $280 / 296$ & $301 / 318$ & $350 / 359$ & $16 / 16.7$ \\
EPA-6-PPG-1000-PU & $280 / 282$ & $300 / 300$ & $350 / 350$ & $17 / 16.3$ \\
\hline
\end{tabular}

* The values in the numerator refer to SC $=60 \mathrm{wt} . \%$, and the values in the denominator refer to $\mathrm{SC}=100 \mathrm{wt} . \%$.

\subsubsection{Thermomechanical Analysis of AEPA-PPG-1000-PU and EPA-PPG-1000-PU}

For AEPA-PPG-1000-PU obtained at SC $=100 \mathrm{wt} . \%$, two transitions are observed on the TMA and DMA curves. A low-intensity transition begins at $50^{\circ} \mathrm{C}$; a high-intensity transition begins at $100-130{ }^{\circ} \mathrm{C}$ (Figure 8). Transitions due to the destruction of supramolecular formations are not observed in this temperature range for AEPA-PPG-1000-PU obtained at SC $=60 \mathrm{wt} . \%$. Judging by the higher thermal stability of the AEPA-PPG-1000-PU samples obtained at SC $=100 \mathrm{wt} . \%$ compared to the AEPA- PPG-1000-PU obtained at SC $=60 \mathrm{wt} . \%$., it can be concluded that the supramolecular structures that break down at $100-130{ }^{\circ} \mathrm{C}$ are clusters resulting from the combination of phosphate anions in the AEPA-PPG-1000-PU matrix $[42,43]$. 


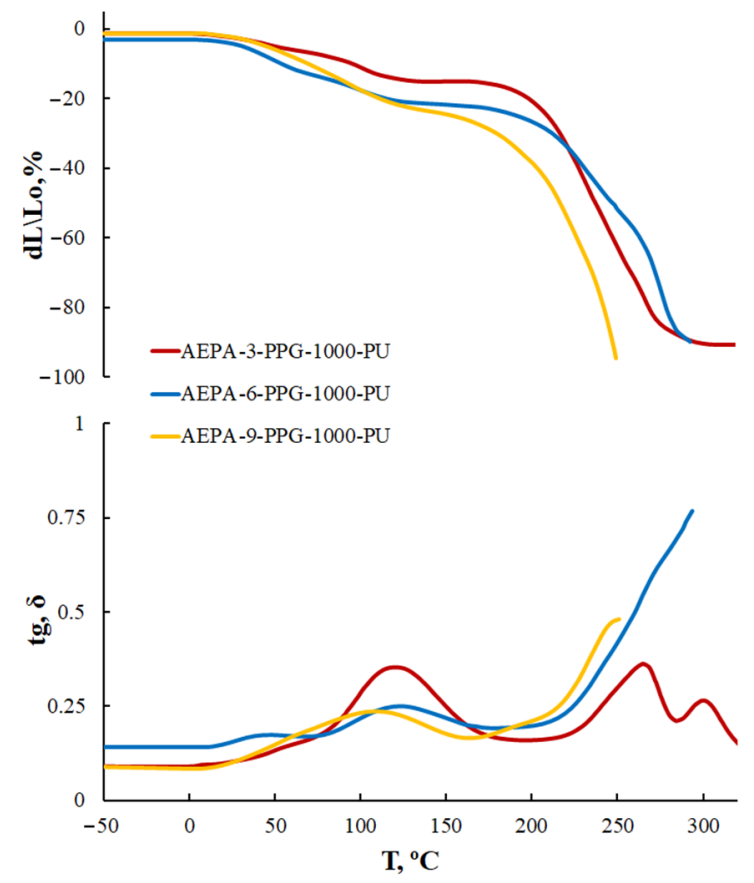

(a)

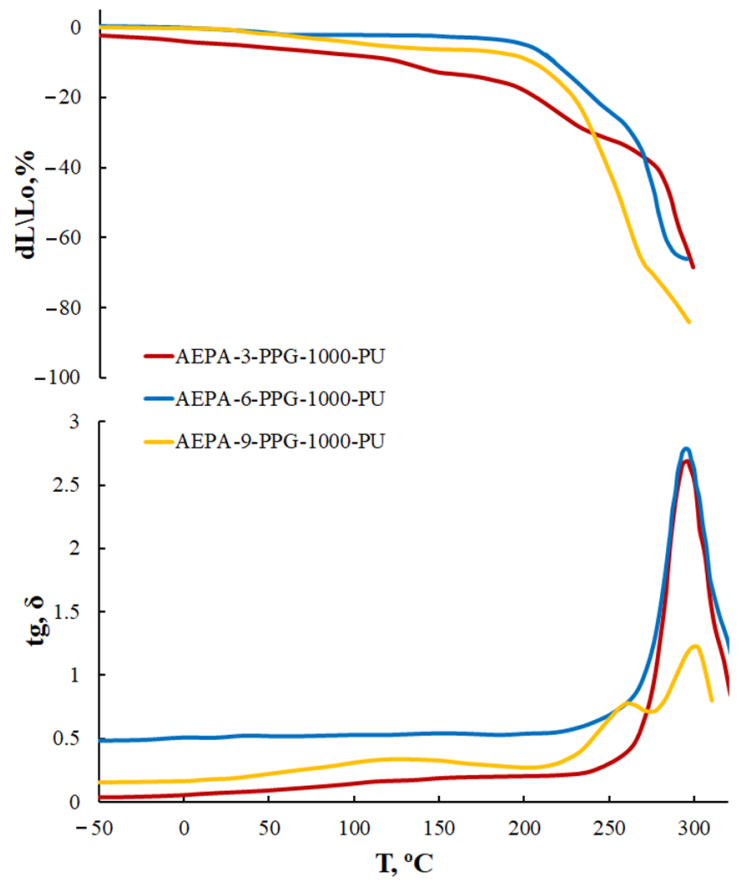

(b)

Figure 8. TMA curves and temperature dependence of the mechanical loss tangent $(\mathrm{tg}, \sigma)$ of AEPA-PPG-1000-PU, obtained at SC $=100$ wt. $\%$ (a); SC $=60$ wt. $\%$ (b).

Apparently, the increase in the concentration of the urethane-forming system based on AEPA-PPG-1000 and PIC up to the synthesis without the use of a solvent is due to intensive clustering processes with the participation of $\mathrm{PO}^{-}$groups that present in AEPA-PPG-1000 (Figure 9).

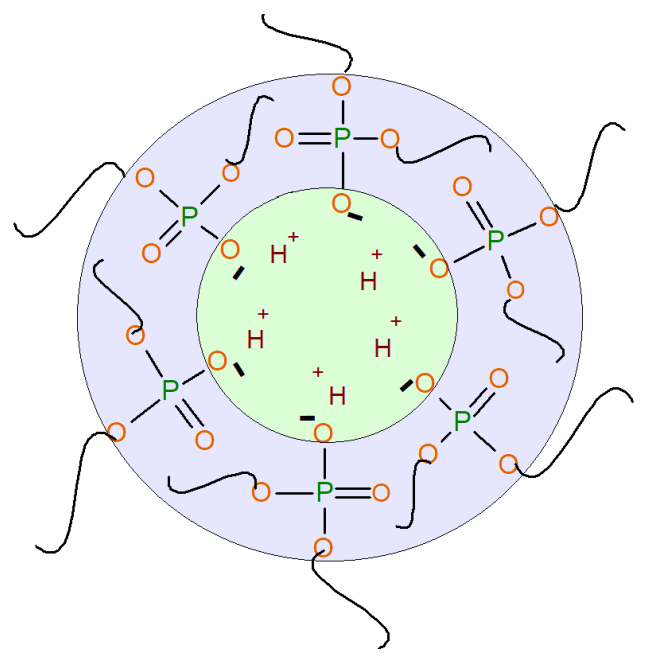

Figure 9. Scheme of the cluster structures formation in the AEPA-PPG-1000-PU.

In the case of EPA-PPG-1000-PU, polyphosphate structures are formed. On the TMA and DMA curves (Figure 10) in the region of $50{ }^{\circ} \mathrm{C}$, a relaxation transition begins due to the clustering of polyphosphate structures. The lower temperature of decomposition of cluster structures for EPA-PPG-1000-PU compared to AEPA-PPG-1000-PU (located in the region of $100{ }^{\circ} \mathrm{C}$ ) is due to the absence of phosphate anions in their composition, which combine during clustering through ionic interactions. For EPA-PPG-1000-PU, the intensity of relaxation transitions depends largely on the content of OPA in the EPA composition 
in comparison with AEPA. This circumstance confirms the conclusions drawn. Thus, in the case of EPA-3-PPG-1000-PU, the content of polyphosphates is still low, whereas, in EPA-9-PPG-1000-PU, it is so high that these structures become bulky and, apparently, no longer participate in clustering.

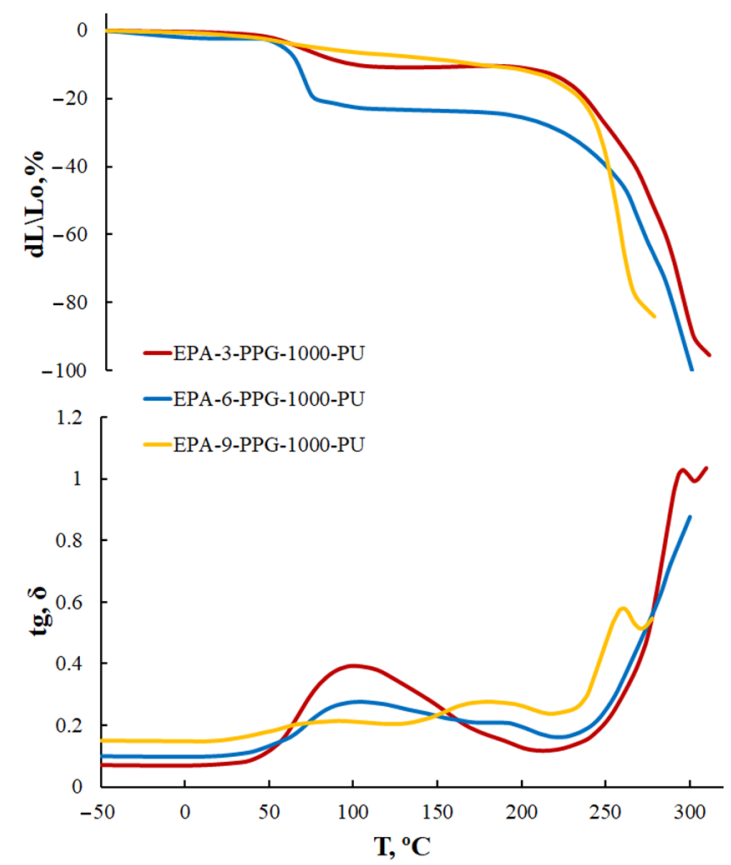

Figure 10. TMA curves and temperature dependence of the mechanical loss tangent $(\operatorname{tg}, \sigma)$ of EPA-PPG-1000-PU, obtained at SC = $100 \mathrm{wt} \%$.

To confirm that the clustering of phosphate anions is a decisive factor in the occurrence of vapor permeability of AEPA-PPG-1000-PU, AEPA-PPG-1000-MIA-PU were synthesized (Figure 11), and their vapor permeability was studied. Compared to the proton, 2-methylimidazole is incomparably large. Consequently, it seems difficult to create the necessary conditions for the clustering of phosphate anions in this case. Indeed, according to the data shown in Figure 12, for AEPA-PPG-1000-MIA-PU, a rapid decrease in vapor permeability values is observed with an increase in the content of 2-methylimidazole in such polyurethanes.

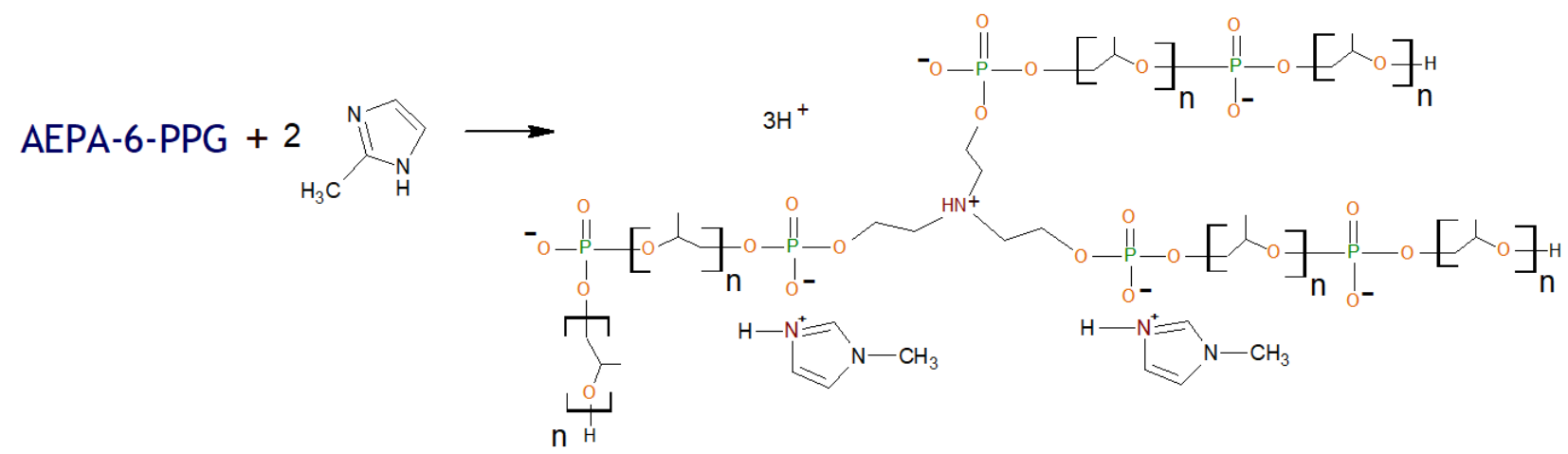

Figure 11. Formation of AEPA-6-PPG-MIA ([MIA]/[TEOA] = 2). 


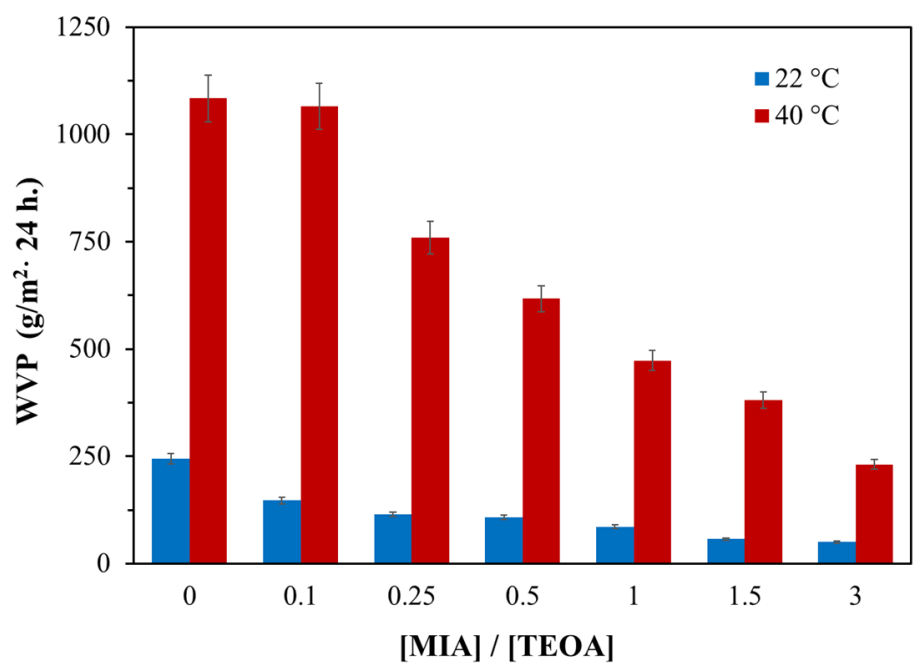

Figure 12. Water vapor permeability coefficients for AEPA-PPG-1000-MIA-PU obtained at $\mathrm{SC}=100 \mathrm{wt} . \%$, on molar ratio [MIA] $/$ TEOA]

\subsection{Membranes Based on AEPA-PEG-400-PU}

When polyether PPG-1000 was replaced by PEG-400 in the synthesis of AEPA-PEG400-PU (SC = $100 \mathrm{wt} . \%$ ), the vapor permeability of film samples increased more than three times (Figure 13). At the same time, the highest values of vapor permeability are observed for AEPA-5-PEG-400-PU.

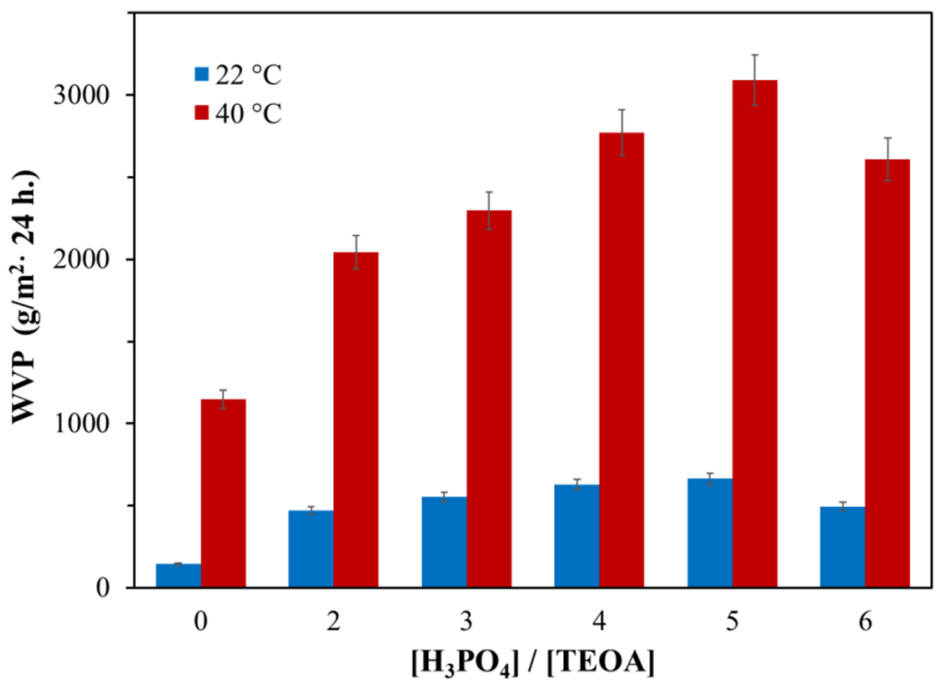

Figure 13. Water vapor permeability coefficients for AEPA-PEG-400-PU obtained at SC $=100 \mathrm{wt} . \%$, on molar ratio $\left[\mathrm{H}_{3} \mathrm{PO}_{4}\right] /[\mathrm{TEOA}]$.

An increase in water vapor permeability values is accompanied by a significant increase in the pervaporation characteristics of AEPA-PEG-400-PU compared to AEPAPPG-1000-PU (Table 1). Similar to the increase in the water vapor permeability coefficient from AEPA-3-PEG-400-PU to AEPA-5-PEG-400-PU, a significant increase in the membrane performance is observed in the same series. With an increase in feed temperature, an increase in flux is accompanied by a regular decrease in selectivity values; however, high values of the pervaporation separation index are observed in all cases. The highest PSI values are achieved for AEPA-5-PEG-400-PU. Water adsorption of AEPA-5-PEG-400-PU (9.4 wt.\%) significantly exceeds the corresponding values obtained for AEPA-5-PPG-1000PU (3.4 wt.\%). 
Nevertheless, with an increase in the molar ratio of $\left[\mathrm{H}_{3} \mathrm{PO}_{4}\right] /[\mathrm{TEOA}]$ to 6 , there is a slight drop in both the vapor permeability coefficient (Figure 13) and the pervaporation efficiency (Table 1) of obtained AEPA-6-PEG-400-PU. The observed effect can be attributed to the fact that an increase in the molar ratio $\left[\mathrm{H}_{3} \mathrm{PO}_{4}\right] /[\mathrm{TEOA}]$ to 6 leads to an increase in the probability of the formation of polyphosphate structures of a non-ionic nature in AEPA-6-PEG-400-PU. A decrease in the values of the vapor permeability coefficient and pervaporation efficiency is accompanied by a corresponding drop in the water absorption of the AEPA-6-PEG-400-PU samples to $7.6 \%$.

\subsubsection{Surface-Active Properties of AEPA-PPG-400/1000 and AEPA-PEG-400}

To explain such significant differences in the efficiency of water transport through membranes based on AEPA-PEG-400-PU and AEPA-PPG-400/1000-PU, comparative studies were made from the point of view of the influence of the molecular weight, hydrophilicity, and hydrophobicity of the polyethers used on the values of the viscosity and density and surface-active properties of AEPA-PEG-400-PU and AEPA-PPG-400/1000-PU, which are ionic polyol components in the synthesis of the studied polyurethanes.

Thus, for PEG-400, the critical micelle concentration (Figure 7c) exceeds the CMC for PPG-1000 (Figure 7b) by 100 times, and the lowest values of surface tension for PEG400 reach $55 \mathrm{mN} / \mathrm{m}$ and are lower in comparison with the lowest $\sigma$ values observed for PPG-1000 $(62 \mathrm{mN} / \mathrm{m})$. Such a large difference in the surfactant properties of PEG-400 and PPG-1000 has a significant effect on the supramolecular organization of AEPA-PEG-400 and AEPA-PPG-1000. Thus, by observing the regularities of changes in surface-active properties, we can determine that AEPA-PPG-1000 exhibits a greater tendency to micelle formation than AEPA-PEG-400.

In order to exclude the influence of molecular weight on the difference in the manifestation of the surface-active properties of AEPA-PEG-400 and AEPA-PPG-1000, similar measurements were carried out for AEPA-PPG-400 (Figure 7d). In this case, the surfaceactive properties of PPG-400 are similar to those of PPG-1000. However, due to the shorter length of the polypropylene component, the surface tension values of AEPA-PPG-400 are higher than AEPA-PPG-1000 (Figure 7b).

\subsubsection{Study of the Viscosity and Density of AEPA-PPG-400/1000 and AEPA-PEG-400}

The fact that the nature of polyether affects the supramolecular organization of the corresponding AEPA can also be observed from the regularities of changes in the values of the viscosity and density of aminoethers of ortho-phosphoric acid. According to Figure 14, the density of AEPA-6-PEG- 400 at $\mathrm{T}=20^{\circ} \mathrm{C}$ relative to the density of PEG-400 increases by almost $0.2 \mathrm{~g} / \mathrm{cm}^{3}$, whereas the density of AEPA-6-PPG- 400 relative to the density of PPG400 and AEPA-PPG-1000 relative to the density of PPG-1000 increases only by $0.05 \mathrm{~g} / \mathrm{cm}^{3}$ and $0.03 \mathrm{~g} / \mathrm{cm}^{3}$, respectively. The density with an increase in the content of ionomeric structures also increases for AEPA-PEG-400-PU (Table 4). Similar patterns are observed for the values of the dynamic viscosity of the studied aminoethers of ortho-phosphoric acid (Figure 14). Thus, the dynamic viscosity of AEPA-6-PEG-400 at $\mathrm{T}=20^{\circ} \mathrm{C}$ relative to the dynamic viscosity of PEG-400 increases almost six times, while the dynamic viscosity of AEPA-6-PPG-1000 relative to the dynamic viscosity of PPG-1000 increases only three times. 


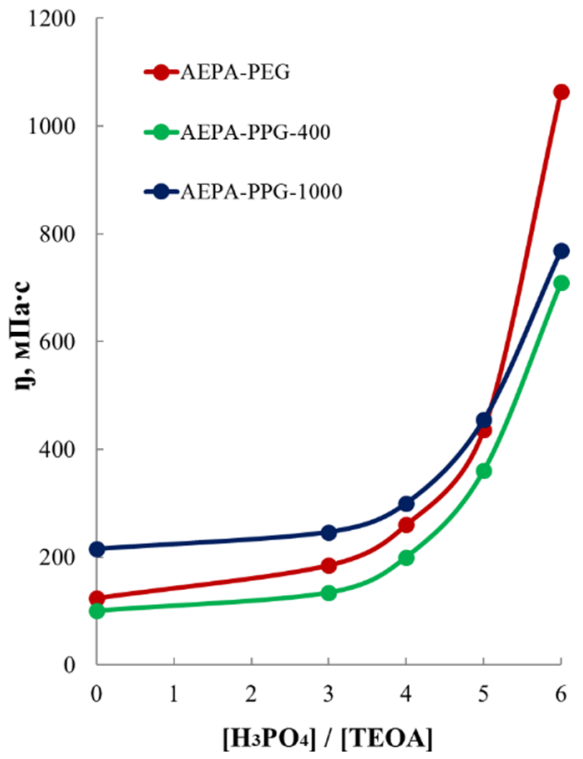

(a)

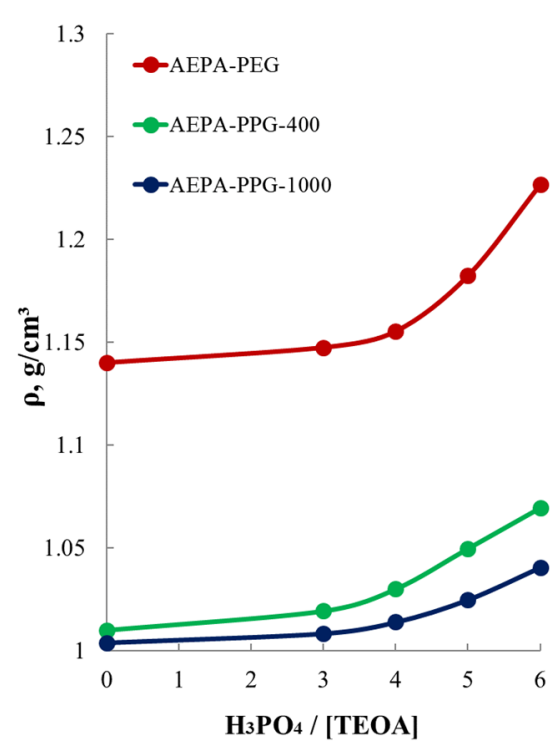

(b)

Figure 14. Dependence of dynamic viscosity (a) and density (b) of AEPA-PEG-400 and AEPA-PPG$400 / 1000$ on molar ratio $\left[\mathrm{H}_{3} \mathrm{PO}_{4}\right]$ :[TEOA]. $\mathrm{T}=20^{\circ} \mathrm{C}$.

Table 4. Density of AEPA-PEG-400-PU.

\begin{tabular}{cc}
\hline Polyurethane & Density, $\mathbf{g} / \mathbf{c m}^{\mathbf{3}}$ \\
\hline AEPA-3-PEG-400-PU & 1.193 \\
AEPA-4-PEG-400-PU & 1.194 \\
AEPA-5-PEG-400-PU & 1.223 \\
AEPA-6-PEG-400-PU & 1.229 \\
AEPA-3-PPG-1000-PU & 1.175 \\
AEPA-4-PPG-1000-PU & 1.184 \\
AEPA-5-PPG-1000-PU & 1.185 \\
AEPA-6-PPG-1000-PU & 1.189 \\
\hline
\end{tabular}

It should be noted that the density of PPG-1000 is noticeably lower than that of PEG-400. At the same time, the surface tension is lower, and the critical micelle concentration is higher for PEG-400 compared to PPG-400. These circumstances lead to different manifestations of surface-active properties, density, and viscosity of AEPA obtained on their basis. As a result, AEPA-PPG-1000 is characterized by the active combination of phosphate anions into clusters that are collected in ion channels surrounded by macro chains of polypropylene glycol-1000. The hydrophobicity of PPG-1000 makes it difficult for water to reach ion channels and move it through the polymer matrix. In the case of AEPA-PEG-400, the tendency to form micellar structures is markedly reduced, which leads to a decrease in the probability of the formation of ionic clusters. At the same time, due to the continuity of the hydrophilic polymer matrix, polyurethanes based on PEG-400 and PIC (PEG-400-PU) are water vapor permeable. The presence of ionic groups in the composition of AEPA-PEG-400-PU increases the mobility of water molecules in such polyurethanes.

\subsubsection{Thermogravimetric Analysis of AEPA-PEG-400-PU}

The conclusions drawn are confirmed by a comparative analysis of the thermal stability of AEPA-PPG-1000-PU and AEPA-PEG-400-PU. As shown above, using the example of AEPA-PPG-1000-PU (Tables 2 and 3), the formation of ionic clusters is accompanied by an increase in the thermal resistance of polyurethanes with an increase in their content of the ionic component. In the case of AEPA-PEG-400-PU, an increase in the content of 
phosphate anions in polyurethanes is not accompanied by an increase in their thermal stability (Table 5).

Table 5. Characteristics of the thermal stability of AEPA-PEG-400-PU (SC $=100 \mathrm{wt} . \%)$ under a nitrogen atmosphere.

\begin{tabular}{ccccc}
\hline Polyurethane & $\mathbf{T}_{\mathbf{5}} \mathbf{\%}\left({ }^{\circ} \mathbf{C}\right)$ & $\mathbf{T}_{\mathbf{1 0}} \mathbf{\%}\left({ }^{\circ} \mathbf{C}\right)$ & $\mathbf{T}_{\mathbf{5 0}} \%\left({ }^{\circ} \mathbf{C}\right)$ & $\begin{array}{c}\text { Coke Content at } \mathbf{6 0 0}{ }^{\circ} \mathbf{C}, \\
\text { wt. } \%\end{array}$ \\
\hline AEPA-3-PEG-400-PU & 291 & 315 & 383 & 26.5 \\
AEPA-4-PEG-400-PU & 292 & 316 & 385 & 27.5 \\
AEPA-5-PEG-400-PU & 296 & 313 & 390 & 28.5 \\
AEPA-6-PEG-400-PU & 290 & 309 & 398 & 30.0 \\
\hline
\end{tabular}

\subsubsection{Thermomechanical Analysis of AEPA-PEG-400-PU}

In addition, the curves of thermomechanical and dynamic mechanical analysis do not show transitions in the range of $100-130^{\circ} \mathrm{C}$, typical for AEPA-PPG-1000-PU (Figure 15).

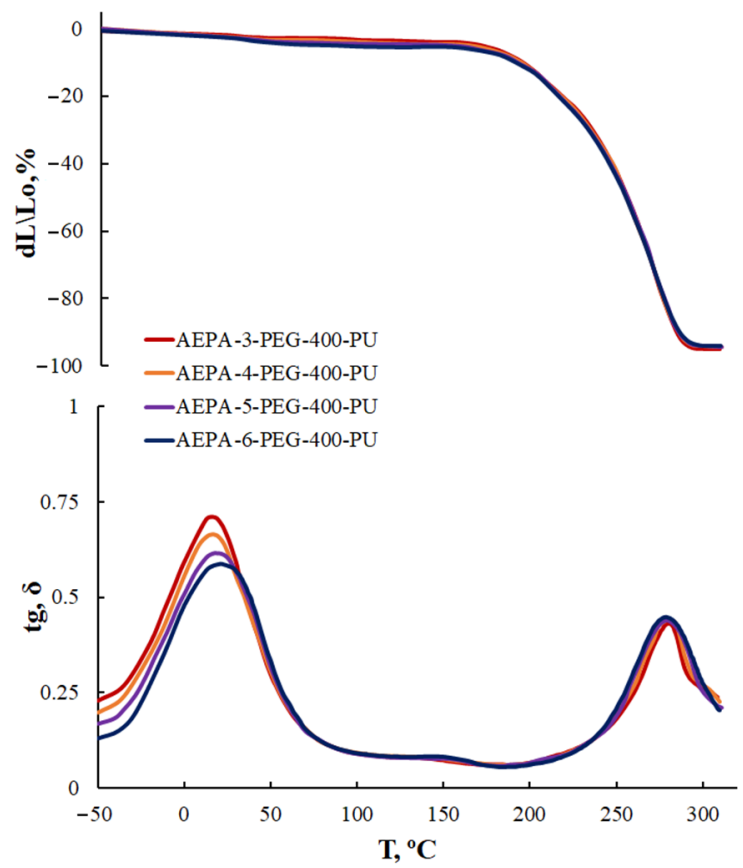

Figure 15. TMA curves and temperature dependence of the mechanical loss tangent $(\mathrm{tg}, \sigma)$ of AEPA-PEG-400-PU, obtained at SC = $100 \mathrm{wt} . \%$.

\subsubsection{Tensile Stress-Strain Analysis of AEPA-PEG-400-PU}

According to Figure 16, samples of polyurethane membranes based on AEPA-PEG-400$\mathrm{PU}$, exhibiting the highest values of vapor permeability and pervaporation characteristics when separating isopropanol/water mixtures, are the most durable. The high strength and heat resistance of AEPA-PEG-400-PU make such polyurethanes promising membrane materials for the pervaporation separation of isopropanol/water mixtures. 


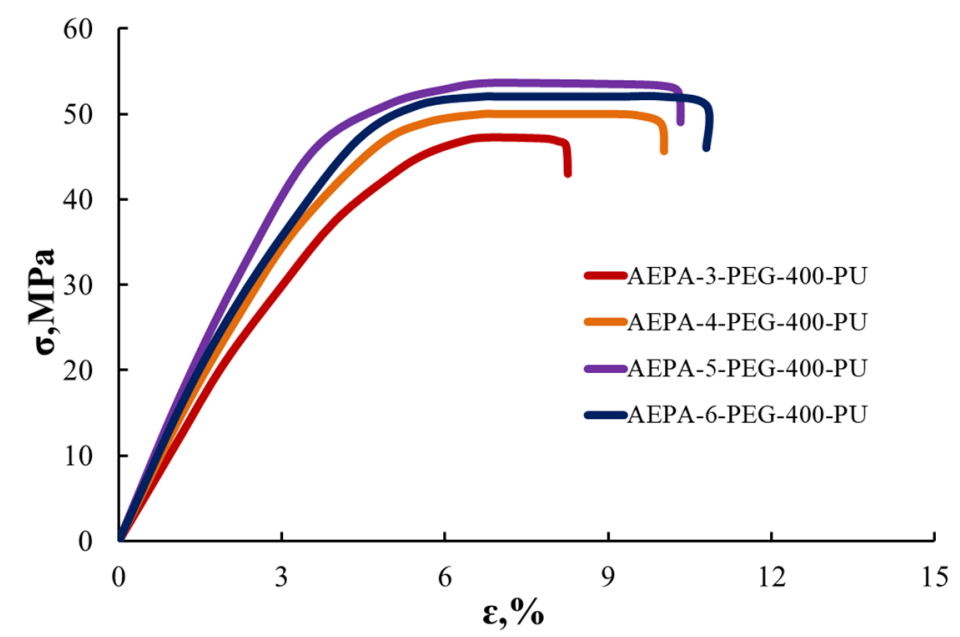

Figure 16. Tensile tests of AEPA-PEG-400-PU, obtained at SC = $100 \mathrm{wt} . \%$.

\section{Conclusions}

In this present work, based on aminoethers of ortho-phosphoric acid synthesized using polyethers of hydrophilic (PEG) and hydrophobic (PPG) nature as lateral flexible chain branches, polyurethane ionomers were obtained as water vapor permeable and pervaporation membranes. From the results obtained in this work, it can be inferred that the water vapor permeability and pervaporation separation index for isopropanol/water mixtures significantly increase by the rising of the content of $\mathrm{H}_{3} \mathrm{PO}_{4}$ in the AEPA-PPG$1000-\mathrm{PU}$ composition and is connected with the clustering of phosphate anions. However, the hydrophobicity of the polypropylene glycol surrounding the clusters makes it difficult for water to move through the polymer matrix. Due to the hydrophilicity of polyethylene glycol, high values of water vapor permeability and pervaporation separation index are achieved for AEPA-PEG-400-PU. As in the case of AEPA-PPG-1000-PU, in AEPA-PEG-400$\mathrm{PU}$, the water vapor permeability and membrane performance noticeably increase with the rising of the content of ionogenic phosphate anions in the obtained polyurethanes.

To substantiate the key role of ionogenic phosphate anions in the formation of water vapor permeability of AEPA-PPG-1000-PU, polyurethanes of a non-ionic nature (EPA-PPG1000-PU) were studied. The water vapor permeability of EPA-PPG-1000-PU also increases with an increase of $\mathrm{H}_{3} \mathrm{PO}_{4}$ content in the composition of EPA. However, the water vapor permeability coefficient values themselves turned out to be more than two times lower compared to the samples of AEPA-PPG-1000-PU.

To confirm that clustering of phosphate anions is a decisive factor in the occurrence of vapor permeability of AEPA-PPG-1000-PU, AEPA-PPG-1000-MIA-PU were synthesized, and their vapor permeability was studied. Compared to the proton, 2-methylimidazole is incomparably large. Consequently, in this case, it seems difficult to create conditions for the clustering of phosphate anions. A rapid decrease in vapor permeability values is observed with an increase in the content of 2-methylimidazole in such polyurethanes. The assumption about the clustering of ionomeric organophosphorus structures in AEPA$\mathrm{PU}$ is also confirmed by the TGA data, thermomechanical analysis, and mechanical loss tangent measurements.

It was found that clustering in polyurethane ionomers is due to the peculiarities of the chemical and supramolecular structure of AEPA. In order to confirm the decisive role of the supramolecular structure on the vapor permeability of AEPA-PPG-1000-PU, polyurethanes based on AEPA-PPG-2000 were synthesized. An increase in the molecular weight of PPG led to a decrease in the water vapor permeability coefficient for AEPA-PPG-2000-PU relative to AEPA-PPG-1000-PU.

By comparing the pervaporation separation index of isopropanol/water mixtures with the known analog polyurethane membranes, we find that the membranes obtained from 
AEPA-PEG have high values. The high strength and heat resistance of AEPA-PEG-400-PU make such polyurethanes promising membrane materials for the pervaporation separation of isopropanol/water mixtures.

Author Contributions: Conceptualization, I.M.D. and A.V.K.; data curation, I.N.Z., A.V.K., A.R.F. and A.V.M.; funding acquisition, I.M.D. and A.V.K.; investigation, O.O.S., I.N.Z. and A.V.M.; project administration, I.M.D. and A.V.K.; resources, O.O.S. and A.R.F.; validation, I.M.D., A.R.F. and A.V.M.; visualization, A.M.G.; writing-original draft, I.M.D., O.O.S. and A.V.K.; writing-review and editing, I.M.D., O.O.S. and A.M.G. All authors have read and agreed to the published version of the manuscript.

Funding: This work was supported by the Russian Science Foundation (grant No. 19-19-00136).

Institutional Review Board Statement: Not applicable.

Informed Consent Statement: Informed consent was obtained from all subjects involved in the study.

Data Availability Statement: The data presented in this study are available on request from the corresponding author.

Acknowledgments: This work was supported by the Russian Science Foundation.

Conflicts of Interest: The authors declare no conflict of interest.

\section{References}

1. Vane, L.M. Membrane materials for the removal of water from industrial solvents by pervaporation and vapor permeation. J. Chem. Technol. Biot. 2019, 94, 343-365. [CrossRef] [PubMed]

2. Jusoh, W.Z.A.W.; Rahman, S.A.; Ahmad, A.L.; Mokhtar, N.M. Modifications on Polymeric Membranes for Isopropanol Dehydration Using Pervaporation: A Review. In Applications of Nanotechnology for Green Synthesis. Nanotechnology in the Life Sciences; Inamuddin, M., Asiri, A.M., Eds.; Springer Nature Switzerland AG: Cham, Switzerland, 2020; Chapter 5; pp. 97-124.

3. Jyothi, M.S.; Reddy, K.R.; Soontarapa, K.; Naveen, S.; Raghu, A.V.; Kulkarni, R.V.; Suhas, D.P.; Shetti, N.P.; Nadagouda, M.N.; Aminabhavi, T.M. Membranes for dehydration of alcohols via pervaporation. J. Environ. Manag. 2019, 242, 415-429. [CrossRef] [PubMed]

4. Zuo, J.; Hua, D.; Maricar, V.; Ong, Y.K.; Chung, T.-S. Dehydration of industrial isopropanol (IPA) waste by pervaporation and vapor permeation membranes. J. Appl. Polym. Sci. 2017, 45086. [CrossRef]

5. Andre, A.; Nagy, T.; Toth, A.J.; Haaz, E.; Fozer, D.; Tarjani, J.A.; Mizsey, P. Distillation contra pervaporation: Comprehensive investigation of isobutanol-water separation. J. Clean. Prod. 2018, 187, 804-818. [CrossRef]

6. Castro-Muñoz, R.; Galiano, F.; Fíla, V.; Drioli, E.; Figoli, A. Mixed matrix membranes (MMMs) for ethanol purification through pervaporation: Current state of the art. Chem. Eng. 2018, 35, 565-590. [CrossRef]

7. Apel, P.Y.; Bobreshova, O.V.; Volkov, A.V.; Volkov, V.V.; Nikonenko, V.V.; Stenina, I.A.; Filippov, A.N.; Yampolskii, Y.P.; Yaroslavtsev, A.B. Prospects of membrane science development. Membr. Membr. Technol. 2019, 1, 45-63. [CrossRef]

8. Zoubeik, M.; Ismail, M.; Salama, A.; Henni, A. New developments in membrane technologies used in the treatment of produced water. Arab. J. Sci. Eng. 2017, 43, 2093-2118. [CrossRef]

9. Ray, S.S.; Iroegbu, A.O.C.; Bordado, J.C. Polymer-Based membranes and composites for safe, potable, and usable water: A survey of recent advances. Chem. Afr. 2020, 3, 593-608. [CrossRef]

10. Malakhov, A.O.; Volkov, A.V. Modification of polymer membranes for use in organic solvents. Russ. J. Appl. Chem. 2020, 93, 14-24. [CrossRef]

11. Fen Yong, W.; Zhang, H. Recent advances in polymer blend membranes for gas separation and pervaporation. Prog. Mater. Sci. 2020, 116, 100713-100745. [CrossRef]

12. Cheng, X.; Pan, F.; Wang, M.; Li, W.; Song, Y.; Liu, G.; Yang, P.; Gao, B.; Wu, H.; Jiang, Z. Hybrid membranes for pervaporation separations. J. Membr. Sci. 2017, 541, 329-346. [CrossRef]

13. Liu, H.-X.; Wang, N.; Zhao, C.; Ji, S.; Li, J.-R. Membrane materials in the pervaporation separation of aromatic/aliphatic hydrocarbon mixtures. Chin. J. Chem. Eng. 2018, 26, 1-16. [CrossRef]

14. Ong, Y.K.; Shi, G.M.; Le, N.L.; Tang, Y.P.; Zuo, J.; Nunes, S.P.; Chung, T.-S. Recent membrane development for pervaporation processes. Prog. Polym. Sci. 2016, 57, 1-31. [CrossRef]

15. Chapman, P.D.; Oliveira, T.; Livingston, A.G.; Li, K. Membranes for the dehydration of solvents by pervaporation. J. Membr. Sci. 2008, 318, 5-37. [CrossRef]

16. Uragami, T. Selective Membranes for Purification and Separation of Organic Liquid Mixtures. In Comprehensive Membrane Science and Engineering, 2nd ed.; Drioli, E., Giorno, L., Fontananova, E., Eds.; Elsevier B. V.: Oxford, UK, 2017; Volume 2, pp. $256-331$.

17. Mulder, M. Basic Principals of Membrane Technology; Kluwer Academic Publishers: London, UK, 1996.

18. Dharupaneedi, S.P.; Kotrappanavar, N.S.; Nadagouda, M.; Raghava, R.K.; Shukla, S.S.; Aminabhavi, T.M. Membrane-based separation of potential emerging pollutants. Sep. Purif. Technol. 2019, 210, 850-866. [CrossRef] [PubMed] 
19. Kamali, M.; Suhas, D.P.; Costa, M.E.; Capela, I.; Aminabhavi, T.M. Sustainability considerations in membrane-based technologies for industrial effluents treatment. Chem. Eng. J. 2019, 368, 474-494. [CrossRef]

20. Lipnizki, F.; Field, R.W.; Ten, P.-K. Pervaporation-based hybrid process: A review of process design, applications and economics. J. Membr. Sci. 1999, 153, 183-210. [CrossRef]

21. Huang, S.; Chang, P.; Tsai, M.; Chang, H. Properties and pervaporation performances of crosslinked HTPB-based polyurethane membranes. Sep. Purif. Technol. 2007, 56, 63-70. [CrossRef]

22. Chao, M.-S.; Huang, S.-L. Epoxidized HTPB-based polyurethane membranes for pervaporation separation. J. Chin. Chem. Soc. 2005, 52, 287-294. [CrossRef]

23. Hu, M.; Gao, L.; Fu, W.; Liu, X.; Huang, F.; Luo, Y.; Huang, C. High-performance interpenetrating polymer network polyurethane pervaporation membranes for butanol recovery. J. Chem. Technol. Biot. 2014, 90, 2195-2207. [CrossRef]

24. Schauer, J.; Bartz, D.; Maroušek, V. Polyurethane pervaporation membranes. Die Angew. Makromol. Chem. 1999, $268,41-45$. [CrossRef]

25. Tsai, M.-H.; Huang, S.-L.; Chang, P.-H.; Chen, C.-J. Properties and pervaporation separation of hydroxyl-terminated polybutadiene-based polyurethane/poly(methyl metharcylate) interpenetrating networks membranes. J. Appl. Polym. Sci. 2007, 106, 4277-4286. [CrossRef]

26. Das, S.; Sarkar, S.; Basak, P.; Adhikari, B. Dehydration of alcohols by pervaporation using hydrophilic polyether urethane membranes. J. Sci. Ind. Res. 2008, 67, 219-227.

27. Yao, L.; Wu, C.; Yang, Z.; Qiu, W.; Cui, P.; Xu, T. Waterborne Polyurethane/Poly(vinyl alcohol) membranes: Preparation, characterization, and potential application for pervaporation. J. Appl. Polym. Sci. 2012, 124, E216-E224. [CrossRef]

28. Xi, T.; Lu, Y.; Ai, X.; Tang, L.; Yao, L.; Hao, W.; Cui, P. Ionic liquid copolymerized polyurethane membranes for pervaporation separation of benzene/cyclohexane mixtures. Polymer 2019, 185, 121948. [CrossRef]

29. Wang, T.; Zhang, Y.; Shi, X.; Wu, L.; Zhang, X.; Zhang, S. Polyurethane hybrid membranes with confined mass transfer channels: The effect of functionalized multi-walled carbon nanotubes on permeation properties. Chem. Eng. Sci. 2019, 201, 191-200. [CrossRef]

30. Wolińska-Grabczyk, A. Effect of the hard segment domains on the permeation and separation ability of the polyurethane-based membranes in benzene/cyclohexane separation by pervaporation. J. Membr. Sci. 2006, 282, 225-236. [CrossRef]

31. Das, S.; Banthia, A.K.; Adhikari, B. Porous polyurethane urea membranes for pervaporation separation of phenol and chlorophenols from water. Chem. Eng. J. 2008, 138, 215-223. [CrossRef]

32. Fragiadakis, D.; Dou, S.; Ralph, H.C.; Runt, J. Molecular mobility, ion mobility, and mobile ion concentration in poly(ethylene oxide)-based polyurethane ionomers. Macromolecules 2008, 41, 5723-5728. [CrossRef]

33. Król, P.; Król, B. Structures, properties and applications of the polyurethane ionomers. J. Mater. Sci. 2019, 55, 73-87. [CrossRef]

34. Daniela, F.; Doina, M.; Stelian, V.; Gabriela, L.; Mariana, C.; Mirela, F.Z. Structure-property relationship of sodium deoxycholate based poly(ester ether)urethane ionomers for biomedical applications. J. Appl. Polym. Sci. 2016, 133, 42921.

35. Bottino, A.; Capannelli, G.; Comite, A.; Costa, C. Synthesis and characterization of polyurethanic proton exchange membranes. J. Fuel Cell Sci. Tech. 2011, 8, 051011. [CrossRef]

36. Chen, K.; Liu, R.; Zou, C.; Shao, Q.; Lan, Y.; Cai, X.; Zhai, L. Linear polyurethane ionomers as solid-solid phase change materials for thermal energy storage. Sol. Energy Mater. Sol. C 2014, 130, 466-473. [CrossRef]

37. Król, B.; Pielichowska, K.; Król, P.; Kędzierski, M. Polyurethane cationomer films as ecological membranes for building industry. Prog. Org. Coat. 2019, 130, 83-92. [CrossRef]

38. Jaudouin, O.; Robin, J.-J.; Lopez-Cuesta, J.-M.; Perrin, D.; Imbert, C. Ionomer-based polyurethanes: A comparative study of properties and applications. Polym. Int. 2012, 61, 495-510. [CrossRef]

39. Luo, J.L.; Liou, Y.J.; Chin, T.M.; Kuo, Y.M.; Chao, D.Y. Water vapor-permeable polyurethane ionomer. J. Appl. Polym. Sci. 2006, 101, 3767-3773. [CrossRef]

40. Davletbaeva, I.M.; Dulmaev, S.E.; Sazonov, O.O.; Gumerov, A.M.; Davletbaev, R.S.; Valiullin, L.R.; Ibragimov, R.G. Polyurethane based on modified aminoethers of boric acid. Polym. Sci. Ser. B 2020, 20, 295-305.

41. Davletbaeva, I.M.; Dulmaev, S.E.; Sazonov, O.O.; Klinov, A.V.; Davletbaev, R.S.; Gumerov, A.M. Water vapor permeable polyurethane films based on the hyperbranched aminoethers of boric acid. RSC Adv. 2019, 9, 23535-23544. [CrossRef]

42. Davletbaeva, I.M.; Sazonov, O.O.; Fazlyev, A.R.; Davletbaev, R.S.; Efimov, S.V.; Klochkov, V.V. Polyurethane ionomers based on amino ethers of orto-phosphoric acid. RSC Adv. 2019, 9, 18599-18608. [CrossRef]

43. Davletbaeva, I.M.; Sazonov, O.O.; Fazlyev, A.R.; Zakirov, I.N.; Davletbaev, R.S.; Efimov, S.V.; Klochkov, V.V. Thermal behavior of polyurethane ionomers based on amino ethers of ortho-phosphoric acid. Polym. Sci. Ser. A 2020, 62, 337-349. [CrossRef] 